\title{
Deep targeted sequencing in pediatric acute Iymphoblastic leukemia unveils distinct mutational patterns between genetic subtypes and novel relapse-associated genes
}

\author{
C. Mårten Lindqvist ${ }^{1}$, Anders Lundmark ${ }^{1}$, Jessica Nordlund ${ }^{1}$, Eva Freyhult ${ }^{2}$, \\ Diana Ekman ${ }^{3}$, Jonas Carlsson Almlöf ${ }^{1}$, Amanda Raine ${ }^{1}$, Elin Övernäs ${ }^{1}$, Jonas \\ Abrahamsson $^{4,9}$, Britt-Marie Frost ${ }^{5,9}$, Dan Grandér ${ }^{6}$, Mats Heyman7,9, Josefine \\ Palle $^{1,5,9}$, Erik Forestier ${ }^{8,9}$, Gudmar Lönnerholm ${ }^{5,9}$, Eva C. Berglund ${ }^{1, *}$, Ann-Christine \\ Syvänen ${ }^{1, *}$ \\ ${ }^{1}$ Department of Medical Sciences, Molecular Medicine and Science for Life Laboratory, Uppsala University, Uppsala, Sweden \\ ${ }^{2}$ Cancer Pharmacology and Computational Medicine, Department of Medical Sciences, National Bioinformatics Infrastructure \\ Sweden, Science for Life Laboratory, Uppsala University, Uppsala, Sweden \\ ${ }^{3}$ Science for Life Laboratory, Department of Biochemistry and Biophysics, Stockholm University, Stockholm, Sweden \\ ${ }^{4}$ Department of Pediatrics, Queen Silvia Children's Hospital, Gothenburg, Sweden \\ ${ }^{5}$ Department of Women's and Children's Health, University Children's Hospital, Uppsala, Sweden \\ ${ }^{6}$ Department of Oncology-Pathology, Karolinska Institute, Stockholm, Sweden \\ ${ }^{7}$ Childhood Cancer Research Unit, Department of Women and Child Health, Astrid Lindgren Children's Hospital, Karolinska \\ University Hospital, Stockholm, Sweden \\ ${ }^{8}$ Department of Medical Biosciences, University of Umeå, Umeå, Sweden \\ ${ }^{9}$ Nordic Society of Pediatric Hematology and Oncology \\ *These authors contributed equally to this work
}

Correspondence to: Ann-Christine Syvänen, email: ann-christine.syvanen@medsci.uu.se

Keywords: acute lymphoblastic leukemia, targeted next generation sequencing, somatic mutation, relapse, clonal evolution

Received: June 25, 2016

Accepted: August 25, 2016

Published: August 31, 2016

\section{ABSTRACT}

To characterize the mutational patterns of acute lymphoblastic leukemia (ALL) we performed deep next generation sequencing of 872 cancer genes in 172 diagnostic and 24 relapse samples from 172 pediatric ALL patients. We found an overall greater mutational burden and more driver mutations in T-cell ALL (T-ALL) patients compared to B-cell precursor ALL (BCP-ALL) patients. In addition, the majority of the mutations in T-ALL had occurred in the original leukemic clone, while most of the mutations in BCP-ALL were subclonal. BCP-ALL patients carrying any of the recurrent translocations ETV6-RUNX1, BCR-ABL or TCF3-PBX1 harbored few mutations in driver genes compared to other BCP-ALL patients. Specifically in BCP-ALL, we identified $A T R X$ as a novel putative driver gene and uncovered an association between somatic mutations in the Notch signaling pathway at ALL diagnosis and increased risk of relapse. Furthermore, we identified EP300, ARID1A and SH2B3 as relapse-associated genes. The genes highlighted in our study were frequently involved in epigenetic regulation, associated with germline susceptibility to $A L L$, and present in minor subclones at diagnosis that became dominant at relapse. We observed a high degree of clonal heterogeneity and evolution between diagnosis and relapse in both BCP-ALL and T-ALL, which could have implications for the treatment efficiency. 


\section{INTRODUCTION}

Acute lymphoblastic leukemia (ALL), the most common pediatric cancer, is a genetically heterogeneous disease that arises from the malignant transformation of lymphoid progenitors at different developmental stages. Although impressive improvements in treatment strategies during recent decades have resulted in survival rates now exceeding $85 \%$, relapsed ALL remains a leading cause of cancer-related death in children [1]. Recurrent large-scale chromosomal aberrations in B-cell precursor ALL (BCPALL) define genetic subtypes, which are used to support therapeutic decisions and correlate with the clinical outcome. Hyperdiploidy (51-67 chromosomes) and the $\mathrm{t}(12 ; 21) E T V 6-R U N X 1$ rearrangement are characteristic for the most common subtypes and are associated with a favorable outcome while MLL rearrangements and hypodiploidy have poor prognosis [2]. About $30 \%$ of the pediatric BCP-ALL patients remain uncharacterized by currently used genetic analyses at ALL diagnosis. The T-cell immunophenotype (T-ALL) comprises about 15\% of pediatric ALL patients [3].

Next generation sequencing technology has opened up new possibilities to identify cancer mutations. Largescale sequencing studies of ALL genomes have identified driver mutations that affect lymphoid development and signaling, tumor suppression as well as cell cycle regulation, Ras and tyrosine signaling, cytokine receptors, and epigenetic regulation (reviewed in [4, 5]). Analyses of matched diagnostic and relapse samples have revealed that relapse-acquired mutations are enriched in genes involved in epigenetic regulation, tumor suppression, Ras signaling and drug metabolism [6-10]. It has also been shown that clonal heterogeneity is common in ALL, and that the dominant clone at relapse often evolves from a minor clone present at diagnosis [9].

In the genetic subtypes of ALL studied to date the prevalence of mutations in driver genes differs markedly [4]. With the exception of the finding that patients with MLL-rearrangements harbor very few somatic mutations [11], quantitative comparison between the different subtypes has yet to be performed. To explore the mutational spectrum in the distinct subtypes of ALL and study clonal evolution on the path to relapse, we sequenced 872 cancer genes in a large set of ALL patients, including relapse samples from a subset of the patients. The design of our study, which includes pediatric ALL patients of multiple subtypes, offers a unique opportunity to compare the pathogenesis between the subtypes.

\section{RESULTS}

To comprehensively characterize the patterns of somatic mutations in pediatric ALL, we performed deep next generation sequencing of the exons of 872 cancer genes (Supplementary Table S1) in samples from 337 patients with pediatric ALL. We included all genes in the Cancer Gene Census (http://cancer.sanger.ac.uk/census), and additional genes that have been shown in previous studies to be related to ALL or other types of cancer. Of the 337 patients, 172 were sequenced individually and are referred to as the "diagnostic cohort". The diagnostic cohort includes 148 BCP-ALL patients and 24 T-ALL patients (Table 1, Supplementary Table S2) from four Swedish pediatric oncology clinics that use harmonized diagnostic criteria and treatment protocols. The BCPALL patients comprised 107 patients from eight recurrent cytogenetic subtypes, 19 patients with a normal karyotype and 22 patients with non-recurrent clonal abnormalities as detected by routine cytogenetic analysis at diagnosis. We sequenced a sample collected at diagnosis from all 172 patients in the diagnostic cohort. For 143 of these patients, referred to as the "core cohort", sequence data from a germline reference sample collected at remission was available [12]. In addition, 24 samples collected at relapse from 19 of the patients were included in the study (Supplementary Table S3). Diagnostic samples from the 165 patients that were not part of the diagnostic cohort were sequenced in pools and are referred to as the "extension cohort". The extension cohort was used for further investigation of genes predicted as putatively associated with relapse. The different cohorts are illustrated in Supplementary Figure S1.

\section{Somatic mutations at ALL diagnosis}

We detected 973 somatic single nucleotide variants (SNVs), 35 deletions and 34 insertions in the 872 sequenced genes in the diagnostic cohort $(n=172)$ (Supplementary Table S4). In the core cohort $(n=143)$ the average number of somatic mutations detected per patient was 3.9 (range 0-31) (Figure 1A, Supplementary Figure S2), after exclusion of one outlier patient with high hyperdiploid (HeH) ALL (ALL_370) who harbored as many as 120 somatic mutations. We detected significantly more somatic mutations in T-ALL patients compared to BCP-ALL patients (averages of 6.4 and 3.5, $p=1.7 * 10^{-4}$, Figure 1A), in line with our previous results from whole genome sequencing of four ALL patients [12]. We found no correlation between number of mutations and age at diagnosis (Supplementary Figure S3), indicating that the difference between the immunophenotype groups was not related to the older age of T-ALL patients (average of 10.1 and 6.9 years in the core cohort). We found no difference in terms of number of mutations between the major BCP-ALL subtypes (Figure 1A). In the 29 BCPALL and T-ALL patients that are not part of the core cohort we identified 13.0 (range 3-35) mutations on average (Supplementary Figure S2). The higher number of mutations detected in these patients is expected, since the lack of a matched germline sample will allow rare germline variants to escape filtering. We found no somatic 
Table 1: Genetic subtypes, clinical outcome and number of driver mutations detected in ALL patients included in the diagnostic cohort $(n=172)$

\begin{tabular}{|c|c|c|c|c|c|c|}
\hline Subtype $^{a}$ & $\begin{array}{c}\text { No. of } \\
\text { patients }^{\mathrm{b}}\end{array}$ & $\begin{array}{l}\text { No. of } \\
\text { relapses }\end{array}$ & $\begin{array}{c}\text { No. of } \\
\text { other events }\end{array}$ & $\begin{array}{c}\text { Patients } \\
\text { with Ras } \\
\text { mutations }\end{array}$ & $\begin{array}{l}\text { No. of driver } \\
\text { mutations per }^{\text {patient }}\end{array}$ & $\begin{array}{l}\text { No. of patients } \\
\text { with no } \\
\text { driver }^{\mathrm{f}}\end{array}$ \\
\hline T-ALL & $24(20)$ & 2 & 4 & $3(12 \%)$ & 2.33 & $5(21 \%)$ \\
\hline $\mathrm{HeH}$ & $47(40)$ & 9 & 0 & $29(62 \%)$ & 1.26 & $13(28 \%)$ \\
\hline $\mathrm{t}(12 ; 21)$ & $36(28)$ & 9 & 1 & $3(8 \%)$ & 0.28 & $28(78 \%)$ \\
\hline Other & $22(20)$ & 7 & 0 & $11(50 \%)$ & 0.68 & $9(41 \%)$ \\
\hline Normal & $19(16)$ & 4 & 1 & $7(37 \%)$ & 0.89 & $7(37 \%)$ \\
\hline $\mathrm{t}(9 ; 22)$ & $8(5)$ & 3 & 2 & $0(0 \%)$ & 0.50 & $4(50 \%)$ \\
\hline 11q23/MLL & $4(4)$ & 2 & 0 & $1(25 \%)$ & 0.50 & $3(75 \%)$ \\
\hline iAMP21 & $4(4)$ & 2 & 0 & $1(25 \%)$ & 0.50 & $3(75 \%)$ \\
\hline $\mathrm{t}(1 ; 19)$ & $4(4)$ & 1 & 0 & $0(0 \%)$ & 0.25 & $3(75 \%)$ \\
\hline $\operatorname{dic}(9 ; 20)$ & $3(2)$ & 1 & 1 & $2(67 \%)$ & 0.67 & $1(33 \%)$ \\
\hline$>67 \mathrm{chr}$ & $1(0)$ & 0 & 0 & $1(100 \%)$ & 2.00 & $0(0 \%)$ \\
\hline
\end{tabular}

${ }^{\mathrm{a}} \mathrm{HeH}$, high hyperdiploidy (51-67 chromosomes); $\mathrm{t}(12 ; 21)$, translocation between the chromosomes $(12 ; 21)(\mathrm{p} 13 ; \mathrm{q} 22)$ ETV6-RUNX1; $\mathrm{t}(9 ; 22)$, translocation between the chromosomes $(9 ; 22)(\mathrm{q} 11 ; \mathrm{q} 34) B C R-A B L 1 ; 11 \mathrm{q} 23 / \mathrm{MLL}$, translocation between $M L L$ and various other genes; iAMP21, intrachromosomal amplification of chromosome $21 ; \mathrm{t}(1 ; 19)$, translocation between the chromosomes $(1 ; 19)(\mathrm{q} 23 ; \mathrm{p} 13) T C F 3-P B X 1 ; \operatorname{dic}(9 ; 20)$, dicentric chromosome $(9 ; 20)(\mathrm{p} 13 ; \mathrm{q} 11) ;>67 \mathrm{chr},>67$ chromosomes; Other, other clonal aberrations; Normal, no genetic aberrations detected and a normal karyotype observed in at least 5 of 25 metaphases. Patients that are not marked T-ALL have the BCP-ALL immunophenotype.

${ }^{b}$ Within parenthesis is the number of patients that are part of the core cohort of patients with a matched germline sample.

'Other events include death in clinical remission 1 (DCR1), secondary malignancy (SMN), resistant disease and failed induction.

${ }^{d}$ Number of non-silent mutations in the genes KRAS, NRAS, PTPN11 and FLT3 are listed.

${ }^{\mathrm{e}}$ Mean number of non-silent mutations in 19 predicted driver genes.

${ }^{\mathrm{f}}$ Number of patients that do not have a non-silent mutation in any of the predicted driver genes.

or germline mutations, e.g. in DNA repair genes, that could explain the apparent hypermutation in the patient ALL_370. However, we cannot exclude the presence of such mutations since only a subset of all genes was sequenced.

The deep coverage in our sequence data (average $638 \times$ ) allowed accurate determination of mutant allele fractions that can be used to identify subclones. The allele fractions (AF) in the core cohort were distributed into two peaks, with an estimated boundary between the peaks at AF 0.32 (Figure 1B). A mutation that was present in the original leukemic clone is expected to be present in all leukemic cells at diagnosis, and have an AF slightly below 0.5 , depending on the percentage of leukemic cells in the sample (typically 80-95\%). Mutations in the peak with low $\mathrm{AF}$ are most likely subclonal, i.e. they occurred after the establishment of the original clone, and are consequently present only in a subset of the leukemic cells. A larger fraction of the somatic mutations in T-ALL compared to BCP-ALL belong to the peak with high AF $\left(p=3.3 * 10^{-10}\right.$, Figure 1B, Supplementary Figure S4), while no trend of a difference was observed between the BCP-ALL subtypes (Supplementary Figure S4). Virtually all mutations in the hypermutated BCP-ALL sample (ALL 370) appeared to be subclonal (Figure 1B), despite an estimated percentage of leukemic cells of $90 \%$ in this sample.

In the core cohort we observed an overall high abundance of $\mathrm{C}>\mathrm{T}$ and $\mathrm{C}>\mathrm{A}$ single-base substitutions across the ALL subtypes (Figure 1C). Based on information on the trinucleotide context of the somatic SNVs (i.e., the nucleotides before and after the SNV), we inferred the predominant mutational signatures in the diagnostic cohort and compared these signatures to previously described signatures [13]. Two such signatures were identified. One of them occurs as the result of an endogenous mutational process that has been observed in all cancer types and is characterized by $\mathrm{C}>\mathrm{T}$ substitution at methylated cytosines. The second signature is characterized by a high proportion of $\mathrm{C}>\mathrm{G}$ substitutions at $\mathrm{TpCpA}$ or TpCpT motifs (Supplementary Figure S5), was predominantly observed in BCP-ALL patients with the $\mathrm{t}(12 ; 21)$ subtype, and is known to be induced by increased activity of the AID/APOBEC family of cytidine deaminases [13]. In comparison to BCP-ALL, the T-ALL patients showed a high fraction of $\mathrm{C}>\mathrm{T}$ substitutions at 

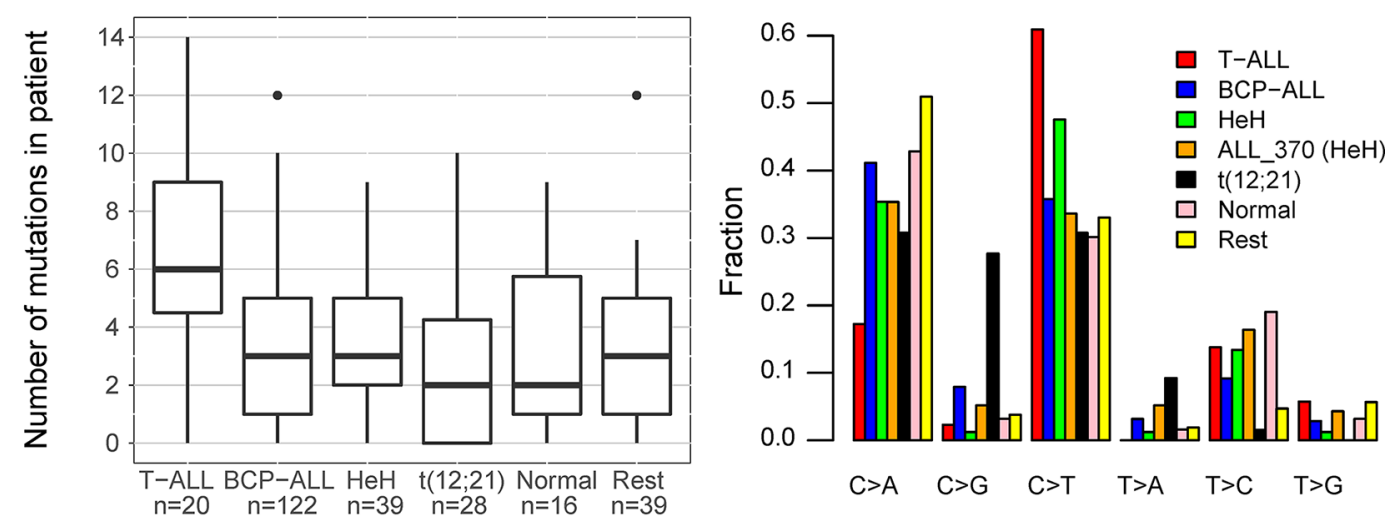

B
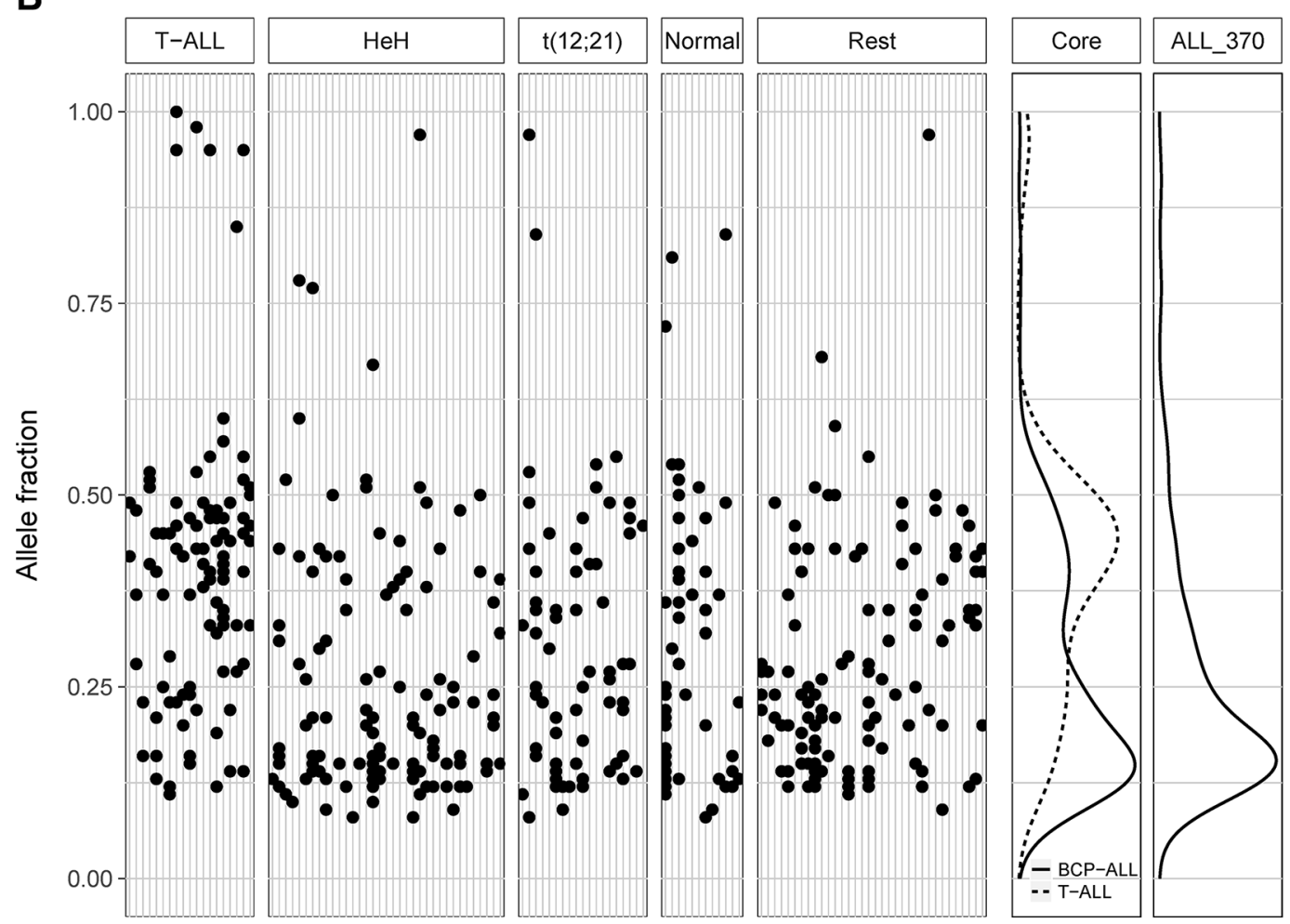

Figure 1: Somatic mutations in acute lymphoblastic leukemia (ALL). (A) Boxplots showing the median number of somatic mutations detected at diagnosis in T-ALL, BCP-ALL, and the major genetic subtypes of BCP-ALL. Results from all patients with paired diagnostic and germline samples that constitute the core cohort are shown, excluding the hypermutated patient with the HeH subtype (ALL_370). The number of mutations is shown on the vertical axis and the patient subgroups, with number of individuals in each group, are indicated on the horizontal axis. BCP-ALL patients with non-recurrent genetic aberrations or any of the rare subtypes $\mathrm{t}(9 ; 22), 11 \mathrm{q} 23 /$ MLL, iAMP21, $\mathrm{t}(1 ; 19), \operatorname{dic}(9 ; 20)$ are combined into one group denoted "Rest". For clarity, one 11q23/MLL patient and two with normal karyotype that have more than 14 mutations $(n=16,16,31)$ are not shown in the figure although they were included in the analysis. (B) Subclonal structure inferred from somatic single nucleotide variants (SNVs) detected at diagnosis in T-ALL and the genetic subtypes of BCP-ALL. The five left-most panels show the allele fraction (AF) of SNVs $(n=610)$ detected in the patients from the core cohort, excluding ALL_370. Each gray vertical line denotes a patient and the black dots represent the mutations identified in each patient. Patients are sorted according to genetic subtype, as indicated above the panels. Mutations with apparently high AF are in most cases located on the $\mathrm{X}$ chromosome in males or in mitochondrial DNA. The two panels to the right show density plots of the AF of the SNVs in the core cohort, and ALL $370(n=117)$, respectively. In the core cohort, T-ALL and BCP-ALL patients are shown separately. The density peak with a maximum AF close to 0.4 corresponds to mutations presumably present in all leukemic cells, and the second peak with a maximum $\mathrm{AF}$ below 0.25 corresponds to subclonal mutations. (C) Pattern of single base substitution in patients with T-ALL, BCP-ALL, and the major genetic subtypes of BCP-ALL. The relative fraction of each substitution type is shown for the ALL patients in the core cohort as indicated by the color key. 
$\mathrm{ApCpG}$ sequence motifs, both in the core cohort analysed here and in the whole genome sequenced patients in our previous study [12] (Supplementary Figures S6-S7).

\section{Driver genes}

To identify the genes involved in the development of pediatric ALL we performed computational screening for driver genes based on the somatic mutations in the diagnostic cohort. We identified 19 putative driver genes (Table 2, Figure 2, Supplementary Figure S8) using a combination of three bioinformatics tools that are based on the assumptions that driver genes have more mutations than expected by chance, more mutations with a high functional impact, or tight clustering of mutations within a gene. Twelve of the 19 genes are well known driver genes in ALL from previous studies, which demonstrates the robustness of our results. We also replicate the finding of RPL10 as a T-ALL driver, which has only been reported once before [14]. KMT2D was previously found by us in the same cohort of ALL patients [12], and the ATRX, $S Y N E 1, F U B P 1, D N A H 5$, and $A B C B 5$ genes, which were all identified in BCP-ALL, have not previously been described as driver genes for ALL.

Because solely the identification of a gene by a computational tool does not imply that the gene is a driver gene, we analyzed the five novel putative driver genes in more detail. Each of the 14 previously described ALL driver genes was expressed on the RNA level and harbored mutations that were present in the original leukemic clone (Table 2, Figure 3). Thus it is plausible that novel driver genes would also show the same pattern in terms of gene expression and clonality, a criterion only fulfilled by ATRX and SYNE1 (Table 2, Figure 3). Computational predictions by PolyPhen-2 and SIFT suggested that virtually all ATRX and SYNE1 mutations could be deleterious (Supplementary Table S5). However, inspection of the protein sequence and structure indicated that none of the SYNE1 mutations have a strong effect on the protein (Supplementary Table S5). In addition, SYNE1 is one of the largest genes in the human genome and its function appears unrelated to hematopoiesis and cancer. Thus, SYNE1 might not be a true driver gene in ALL. In contrast, several of the ATRX mutations are likely to have an effect on the protein (Supplementary Table S5), and this gene might represent a novel ALL driver gene.

We observed major differences in terms of driver genes between T-ALL and BCP-ALL patients. The most prevalent driver mutations were in NOTCH1 in T-ALL and in the Ras signaling pathway (NRAS, KRAS, PTPN11 and FLT3) in BCP-ALL (Figure 2, Supplementary Figure S8). We found a non-frameshift deletion in the known ALL driver gene FLT3 in five $\mathrm{HeH}$ patients, which to our knowledge has not previously been reported as a recurrent mutation in ALL. T-ALL patients harbored on average more mutations in putative driver genes than BCP-ALL patients, and were less likely to lack a driver mutation $\left(\mathrm{p}=9.7 * 10^{-5}\right.$, Table 1, Supplementary Figure S9). Significant differences in number of putative driver mutations were also observed between the BCP-ALL subtypes, with most driver mutations in patients with $\mathrm{HeH}$ and few mutations in patients with the recurrent translocations ETV6-RUNX1, BCR-ABL, or TCF3-PBX1 ( $p=1.9 * 10^{-5}$, Table 1, Supplementary Figures S9). The driver mutations in the Ras signaling pathway displayed a similar pattern, with few mutations in patients with recurrent translocations (Supplementary Figure S10). The only gene that was identified as a driver in the $\mathrm{t}(12 ; 21)$ BCP-ALL patients was WHSCl (NSD2) (Supplementary Figure S8). A total of 76 patients (44\%) in the diagnostic cohort did not harbor any non-silent mutation in the 19 predicted driver genes (Table 1). In contrast to a previous study in chronic lymphoblastic leukemia, where patients with more driver mutations displayed a lower overall survival [15], we found no correlation between the number of putative driver mutations and clinical outcome (Supplementary Figure S11).

\section{Genes and pathways associated with relapse}

To identify genes and pathways that are associated with relapse in ALL, we performed survival analysis using Gray's test based on the somatic mutations detected in the diagnostic cohort. We analyzed all genes that harbored non-silent mutations in at least five patients in a specific patient subgroup ( $n=0-10$ genes per group). No single gene was found to be significantly associated with relapse. In a separate analysis, mutations were assigned to pathways according to the Kyoto Encyclopedia of Genes and Genomes (KEGG). All pathways that were mutated in at least five patients in a subgroup ( $n=10-60$ pathways per group) were included in the analysis. We found an increased risk of relapse for BCP-ALL patients with a mutation in the Notch signaling pathway $(p=0.0237$, Figure 4). Mutations in genes in the Notch pathway in patients that relapsed included nonsynonymous SNVs (nsSNVs) in CREBBP $(n=3), \operatorname{EP300}(n=1)$, MAML2 $(n=1), \operatorname{HDAC2}(n=1), \operatorname{NOTCH} 2(n=1)$ and DTX1 $(n=1)$, all of which are expressed in BCP-ALL (Supplementary Table S5). Computational predictions and functional evidence suggest that each of these patients harbored a damaging mutation in the Notch pathway at diagnosis (Supplementary Table S5). We also identified Notch pathway mutations that were called only at relapse in $\operatorname{CREBBP}(n=3)$, which is a known relapse-associated gene in ALL [6], EP300 $(n=2), \operatorname{NOTCH}(n=1)$ and NOTCH2 $(n=1) . E P 300$ is a paralog to CREBBP which has not yet been shown as relapse-associated in ALL, and the recurrent mutations in this gene are thus highly interesting. Investigation of the extension cohort identified one additional non-silent mutation in EP300, and the patient that harbored this mutation also relapsed (Table 3, Supplementary Table S5). 
Table 2: Driver genes identified in ALL patients included in the diagnostic cohort $(n=172)$

\begin{tabular}{|c|c|c|c|c|c|}
\hline Gene & Gene description & Cytoband & $\begin{array}{c}\text { GEX } \\
(\text { FPKM) }\end{array}$ & ALL subtype $^{b}$ & $\begin{array}{c}\text { ALL } \\
\text { association }\end{array}$ \\
\hline NOTCH1 & notch 1 & $9 \mathrm{q} 34.3$ & 7.8 & T-ALL & T-ALL [21] \\
\hline PTEN & phosphatase and tensin homolog & $10 \mathrm{q} 23$ & 152 & T-ALL & T-ALL [55] \\
\hline PHF6 & PHD finger protein 6 & $\mathrm{Xq} 26$ & 13.1 & T-ALL & T-ALL [56] \\
\hline FBXW7 & $\begin{array}{l}\text { F-box and WD } \\
\text { containing } 7\end{array}$ & $4 \mathrm{q} 31.23$ & 23.7 & T-ALL & T-ALL [57] \\
\hline DNM2 & dynamin 2 & $19 \mathrm{p} 13.2$ & 11.2 & T-ALL & T-ALL [27] \\
\hline RPL10 & ribosomal protein L10 & $\mathrm{Xq} 28$ & 339.1 & T-ALL & T-ALL [14] \\
\hline NRAS & $\begin{array}{l}\text { neuroblastoma RAS viral oncogene } \\
\text { homolog }\end{array}$ & $1 \mathrm{p} 13.2$ & 31 & $\begin{array}{l}\text { BCP-ALL, } \\
\text { HeH, normal, } \\
\text { T-ALL }\end{array}$ & ALL [58] \\
\hline KRAS & KRAS proto-oncogene, GTPase & $12 \mathrm{p} 12.1$ & 10.9 & $\begin{array}{l}\text { BCP-ALL, } \\
\mathrm{HeH}\end{array}$ & ALL [59] \\
\hline PTPN11 & $\begin{array}{l}\text { protein tyrosine phosphatase, non- } \\
\text { receptor type } 11\end{array}$ & $12 \mathrm{q} 24.1$ & 48.6 & $\begin{array}{l}\text { BCP-ALL, } \\
\mathrm{HeH}\end{array}$ & $\begin{array}{l}\text { BCP-ALL } \\
{[60]}\end{array}$ \\
\hline FLT3 & fms related tyrosine kinase 3 & $13 q 12$ & 61.3 & $\begin{array}{l}\text { BCP-ALL, } \\
\mathrm{HeH}\end{array}$ & $\begin{array}{l}\mathrm{HeH}[61], \\
11 \mathrm{q} / \mathrm{MLL} \\
{[62]}\end{array}$ \\
\hline CREBBP & CREB binding protein & $16 \mathrm{p} 13.3$ & 9 & $\begin{array}{l}\text { BCP-ALL, } \\
\mathrm{HeH}\end{array}$ & $\begin{array}{l}\text { BCP-ALL } \\
{[6]}\end{array}$ \\
\hline KMT2D & lysine methyltransferase 2D & $12 \mathrm{q} 13.12$ & 15.4 & BCP-ALL & ALL [12] \\
\hline WHSC1 & Wolf-Hirschhorn syndrome candidate 1 & $4 p 16.3$ & 48.2 & $\begin{array}{l}\text { BCP-ALL, } \\
\mathrm{t}(12,21)\end{array}$ & $\mathrm{t}(12 ; 21)[63]$ \\
\hline IL7R & interleukin 7 receptor & $5 \mathrm{p} 13$ & 39.9 & $\begin{array}{l}\text { BCP-ALL, } \\
\text { normal, T-ALL }\end{array}$ & $\begin{array}{l}\text { BCP-ALL } \\
\text { [64], T-ALL } \\
{[65]} \\
\end{array}$ \\
\hline ATRX & $\begin{array}{l}\text { alpha thalassemia/mental retardation } \\
\text { syndrome X-linked }\end{array}$ & $\mathrm{Xq} 21.1$ & 41.1 & BCP-ALL & \\
\hline SYNE1 & $\begin{array}{l}\text { spectrin repeat containing nuclear } \\
\text { envelope protein } 1\end{array}$ & $6 \mathrm{q} 25.2$ & 12.7 & $\begin{array}{l}\text { BCP-ALL, } \\
\mathrm{HeH}\end{array}$ & \\
\hline FUBP1 & far upstream element binding protein 1 & $1 \mathrm{p} 31.1$ & 102.4 & BCP-ALL & \\
\hline DNAH5 & dynein axonemal heavy chain 5 & $5 \mathrm{p} 15.2$ & 0 & BCP-ALL & \\
\hline ABCB5 & $\begin{array}{l}\text { ATP binding cassette subfamily B } \\
\text { member } 5\end{array}$ & $7 \mathrm{p} 14$ & 0.1 & BCP-ALL & \\
\hline
\end{tabular}

${ }^{a}$ The shown expression value represents the mean of 18 T-ALL samples (for the genes identified as drivers only in T-ALL) or 27 BCP-ALL samples (for the remaining genes). FPKM, fragments per kilobase of transcripts per million mapped reads. ${ }^{\mathrm{b}}$ The ALL immunophenotype(s) and subtype(s) in which the gene was identified as a driver. BCP-ALL signifies that the gene was identified as driver in the set of all BCP-ALL samples.

A mutation that was called at relapse but not at diagnosis has either occurred after the diagnostic sample was collected or it was present at diagnosis in a subclone too small to be identified by standard variant calling methods (see the next section on clonal evolution). Since in both cases, the mutation is present in a much larger proportion of leukemic cells at relapse compared to diagnosis and could have been involved in driving the relapse, we refer to these mutations collectively as "relapse-gained". In addition to the CREBBP and EP300 mutations described above, recurrent non-silent relapsegained mutations were detected in NOTCH1 $(n=3)$, $\operatorname{KRAS}(n=2)$ and NT5C2 $(n=2)$, all of which are known in ALL, as well as SYNE1 $(n=2)$ and MUC5B $(n=2)$. Both relapse-gained mutations in SYNE1 appear benign (Supplementary Table S5), and MUC5B is not expressed in ALL. By joint analysis of relapse-gained and diagnostic mutations, including the extension cohort, we found that BCP-ALL patients with $E B F 1$ or $A F F 3$ mutations and T-ALL patients with ARIDIA mutations 
Table 3: Somatic mutations in genes putatively associated with ALL relapse

\begin{tabular}{|c|c|c|c|c|c|c|c|c|c|}
\hline Gene & $\begin{array}{l}\text { Protein } \\
\text { change }\end{array}$ & Patient $^{\mathrm{a}}$ & Subtype $^{b}$ & SIFT $^{c}$ & $\mathbf{P P 2}^{\mathrm{d}}$ & Origin $^{e}$ & $\mathbf{A} \mathbf{F}^{\mathrm{f}}$ & $\begin{array}{c}\text { GEX } \\
(\text { FPKM })^{g}\end{array}$ & Functional evidence $^{\mathrm{h}}$ \\
\hline AFF3 & p.I941V & ALL_260 & $\mathrm{t}(9 ; 22)$ & $\mathrm{T}$ & B & Dia (E) & NA & 87 & $\begin{array}{l}\text { Small change in amino } \\
\text { acid properties * }\end{array}$ \\
\hline AFF3 & p.E811K & ALL_784 & $\mathrm{HeH}$ & $\mathrm{T}$ & $\mathrm{D}$ & Dia (D) & 0.46 & 87 & $\begin{array}{l}\text { Disordered part of } \\
\text { the protein that folds } \\
\text { upon binding. Could } \\
\text { affect protein-protein } \\
\text { interaction [66] }\end{array}$ \\
\hline AFF3 & NA & ALL_128 & other & NA & NA & Rel 2 & 0.16 & 87 & Splice site SNV $*$ \\
\hline ARID1A & p.T626P & ALL_217 & T-ALL & $\mathrm{D}$ & $\mathrm{D}$ & Dia (E) & NA & 20.8 & $\begin{array}{l}\text { Close to DNA-binding } \\
\text { where the proline's } \\
\text { ability to bend the } \\
\text { backbone is likely to } \\
\text { affect the binding [67] * }\end{array}$ \\
\hline ARID1A & p.R893X & ALL_358 & T-ALL & NA & NA & Rel 1 & 0.30 & 20.8 & $\begin{array}{l}\text { Premature stop codon } \\
\text { that removes the } \\
\text { majority of the protein * }\end{array}$ \\
\hline EBF1 & p.V440L & ALL_54 & $\mathrm{HeH}$ & $\mathrm{T}$ & B & Dia (E) & NA & 131.1 & $\begin{array}{l}\text { Small change in amino } \\
\text { acid properties * }\end{array}$ \\
\hline EBF1 & p.N100fs & ALL_27 & normal & NA & NA & Rel 1 & 0.41 & 131.1 & $\begin{array}{l}\text { Frameshift that removes } \\
\text { the majority of the } \\
\text { protein } *\end{array}$ \\
\hline EBF1 & p.N100RN & ALL_27 & normal & NA & NA & Rel 1 & 0.41 & 131.1 & $\begin{array}{l}\text { In DNA-binding domain } \\
\text { but far away from the } \\
\text { DNA binding site [68, } \\
69]^{*}\end{array}$ \\
\hline EBF1 & p.N100FGN & ALL_168 & $\mathrm{t}(9 ; 22)$ & NA & NA & Dia (D) & 0.40 & 131.1 & $\begin{array}{l}\text { In DNA-binding domain } \\
\text { but far away from the } \\
\text { DNA binding site [68, } \\
69]^{*}\end{array}$ \\
\hline EP300 & p.N700K & ALL_365 & iAMP21 & $\mathrm{T}$ & D & Dia (D) & 0.24 & 10.7 & $\begin{array}{l}\text { Medium change in } \\
\text { amino acid properties * }\end{array}$ \\
\hline EP300 & p.Q734R & ALL_821 & other & $\mathrm{T}$ & D & Dia (E) & NA & 10.7 & $\begin{array}{l}\text { Small change in amino } \\
\text { acid properties * }\end{array}$ \\
\hline EP300 & p.A794T & ALL_244 & other & $\mathrm{T}$ & $\mathrm{D}$ & Rel 1 & 0.49 & 10.7 & $\begin{array}{l}\text { Medium change in } \\
\text { amino acid properties * }\end{array}$ \\
\hline EP300 & p.S225SN & ALL_5 & $\begin{array}{l}\text { 11q23/ } \\
\text { MLL }\end{array}$ & NA & NA & Rel 2 & 0.27 & 10.7 & $\begin{array}{l}\text { Located close to a } \\
\text { region involved in } \\
\text { various protein-protein } \\
\text { interactions } *\end{array}$ \\
\hline
\end{tabular}

${ }^{a}$ All patients relapsed except ALL_168 who suffered from a secondary malignancy.

${ }^{\mathrm{b}}$ For explanation of the subtypes, see legend to Table 1.

'SIFT predictions: D, damaging; T, tolerated.

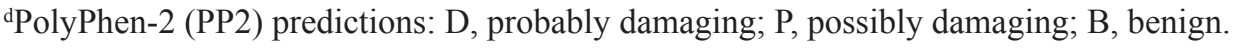

'Indicates at which disease state (Dia, diagnosis; Rel 1, first relapse; Rel 2, second relapse) and in which cohort (D, diagnostic; E, extension) the mutation was first called.

${ }^{\mathrm{f}}$ The mutations identified in the extension cohort have no allele fraction (AF) since they were called in pools of samples.

'The shown expression value represents the mean of 18 T-ALL samples (for ARID1A) or 27 BCP-ALL samples (for the remaining genes). FPKM, fragments per kilobase of transcripts per million mapped reads.

${ }^{\mathrm{h}} \mathrm{A}$ star indicates that no structural information was available for this region of the protein.

Additional information about these mutations is available in Supplementary Table S5. 
relapsed frequently. Six patients, of which five relapsed and one experienced a secondary malignancy, harbored mutations in EBF1 or AFF3 (Table 3, Supplementary Table S5). However, computational prediction and structural information indicate that several of these mutations have no major effect on protein function (Table 3, Supplementary Table S5). Thus, although these genes are highly relevant in the context of BCP-ALL, their putative association with relapse needs to be further investigated in larger studies. Out of four T-ALL patients in the diagnostic and extension cohorts who relapsed, two harbored mutations in ARIDIA. The mutations included a nonsense SNV and a nsSNV that introduced a proline at a position where it is likely to disrupt DNA binding (Table 3, Supplementary Table S5). Thus both mutations in $A R I D 1 A$ are predicted to have a strong functional impact on the encoded protein.

\section{Clonal evolution between diagnosis and relapse}

In the 19 patients from whom paired diagnosisrelapse samples were sequenced we identified 313 somatic mutations, including 69 mutations that were called only at diagnosis and 95 that were relapse-gained (Supplementary Tables S4, S6 and S7). We detected subclonal mutations at diagnosis and gain and/or loss of mutations at relapse in each of the 19 patients. Among the ALL driver genes, gain and loss of mutations were particularly common in the genes from the Ras pathway, with seven out of nine non-silent diagnostic Ras mutations lost at relapse and six relapse-gained mutations (Figure 5). Since we sequenced to a high coverage, we were able to determine whether mutations that were only called at relapse were in fact present in a minor subclone already at diagnosis by examining single reads that supported the variant. We found that 20 of the 95 relapse-gained mutations were detectable at low level $(\mathrm{AF}<2 \%)$ at diagnosis, and six

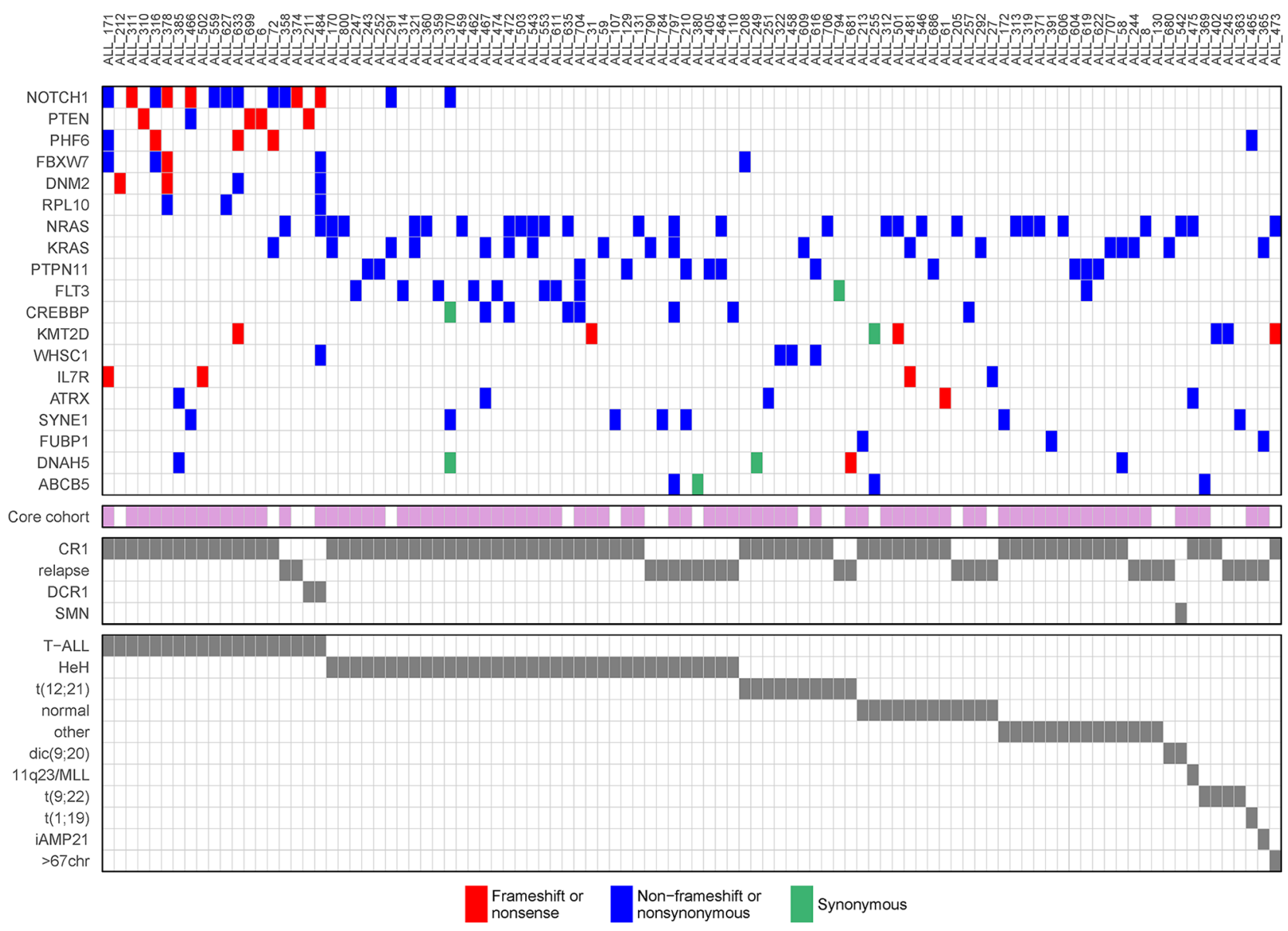

Figure 2: Driver genes in acute lymphoblastic leukemia (ALL). Driver genes identified by computational analysis of somatic mutations detected at ALL diagnosis. In the top panel, each row represents a gene, each column represents an ALL patient, and each colored box indicates a mutation. Patients with at least one mutation in any of the predicted driver genes are shown. For patients with more than one mutation in the same gene, the color is prioritized according to the order shown in the color key in the figure. The violet bars below each column in the top panel indicate patients that are part of the core cohort with a matched germline sample. The clinical outcome and the genetic subtype of each patient are shown by grey bars in the two bottom panels. CR1, clinical remission 1; DCR1, death in CR1; SMN, secondary malignancy. 


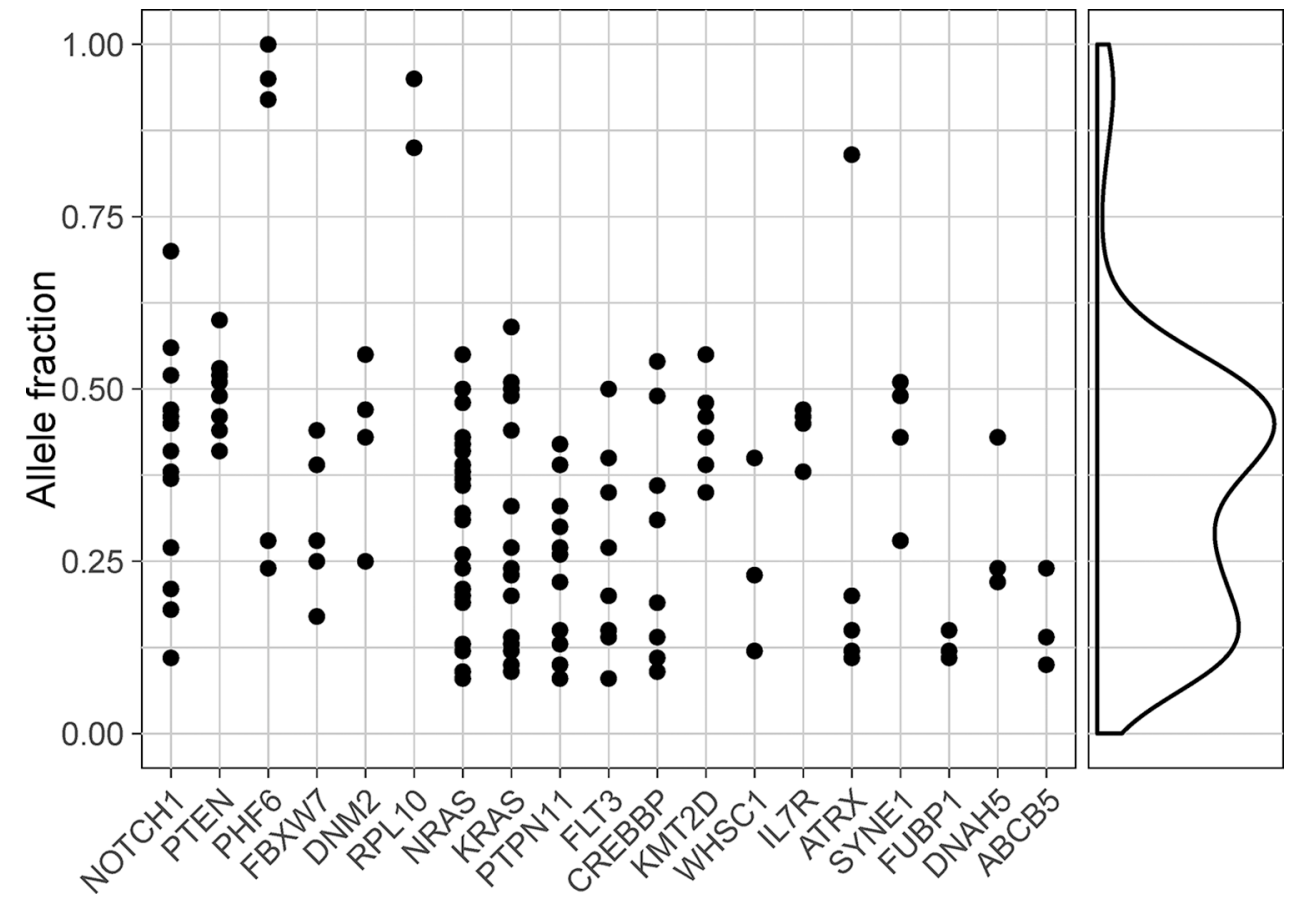

Figure 3: Allele fractions of somatic mutations in driver genes. Allele fractions of all non-silent somatic mutations $(n=167)$ detected in predicted driver genes at ALL diagnosis. Allele fractions are plotted on the vertical axis and gene names are shown on the horizontal axis. To the right of the large panel is a density plot which includes all mutations shown in the figure.

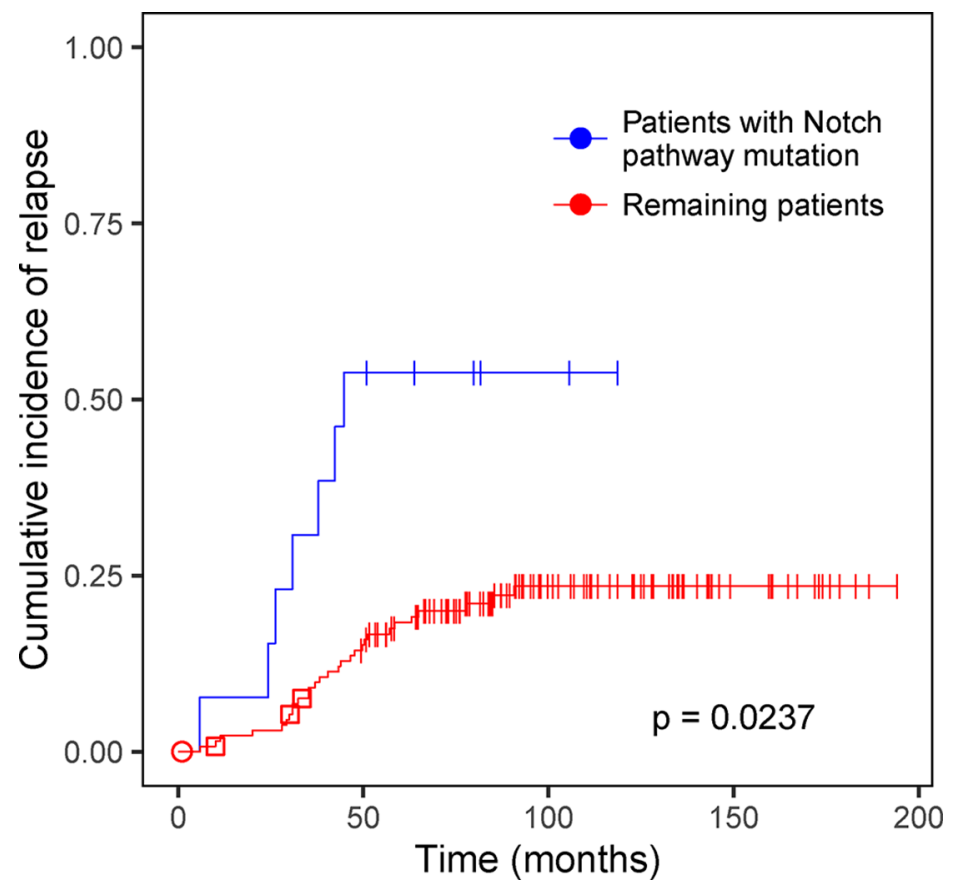

Figure 4: Survival analysis of acute lymphoblastic leukemia (ALL) patients with and without mutations in the Notch signaling pathway. Cumulative incidence of relapse in BCP-ALL patients in the diagnostic cohort with mutations in the Notch signaling pathway. The blue line represents patients that have at least one non-silent mutation in the Notch signaling pathway and the red line represents the remaining BCP-ALL patients. The Bonferroni-corrected Gray's test $p$-value is shown. The symbols shown on the cumulative incidence curves represent the clinical outcome of patients that did not relapse. Vertical bars indicate clinical remission 1 (CR1), circles indicate resistant disease, and squares indicate secondary malignancy. 
additional mutations that were called only at the second relapse were detectable at low level at the first relapse (Figure 6A, Supplementary Figure S12). These results indicate that relapse clones are often derived from minor subclones that are present already at diagnosis and survive therapy. In contrast, only six of the 69 mutations called only at diagnosis were detectable at relapse, which indicates that it is a rare event that the prevalence of a clone is diminished without being eradicated.

While the allele fractions of mutations that were called at both diagnosis and first relapse were in most cases relatively similar (Figure 6A), nine patients showed evidence of an expanding clone. Such rising clones are particularly interesting because they could harbor mutations that confer resistance to therapy. We have selected two BCP-ALL patients with non-recurrent clonal aberrations (ALL_128 and ALL_244) and one T-ALL patient (ALL_358) to illustrate the patterns of rising clones (Figure 6B-6D). In ALL_128 we observed simultaneous expansion of a clone harboring loss-of-function mutations in SH2B3 and ETV6 and loss of the wild type alleles of these genes which resulted in mutations present in a large proportion of leukemic cells (Figure 6B). We inferred two distinct rising clones in both ALL_244 (Figure 6C) and ALL_358 (Figure 6D). Two of these clones harbored mutations in EP300 or ARID1A, which were both identified as putatively associated with relapse (see previous section on genes associated with relapse), and one clone harbored a mutation in the previously known relapse-associated gene $N T 5 C 2[7,16]$.

\section{DISCUSSION}

In the current study, we describe somatic mutations detected by deep targeted sequencing in a large cohort of pediatric ALL patients comprising different genetic subtypes. In light of the recent demonstration that the strategies used for both sequencing and data analysis can greatly influence the results of somatic variant calling [17], our study design is particularly useful for comparison of the mutational landscapes between immunophenotypes and subtypes of ALL. We found several differences between the T-ALL and BCP-ALL groups. These distinctive differences include an overall larger number of mutations and a larger number of mutations in driver genes in T-ALL. The high sequence depth of our study allowed accurate determination of allele fractions, which enabled us to observe that a higher proportion of the somatic mutations in T-ALL than in BCP-ALL were present already in the original leukemic clone. A possible explanation for this is that T-ALL generally has a faster and more explosive course than BCP-ALL, thus there has been less time to collect additional mutations since the establishment of the ancestral leukemic clone.

A striking difference between the BCP-ALL subtypes is that the patients carrying the recurrent fusion genes ETV6-RUNX1, BCR-ABL or TCF3-PBX1 harbored exceptionally few mutations in known driver genes compared to the other BCP-ALL patients. This finding may indicate that the fusion genes themselves act as strong drivers, so that few or no additional driver

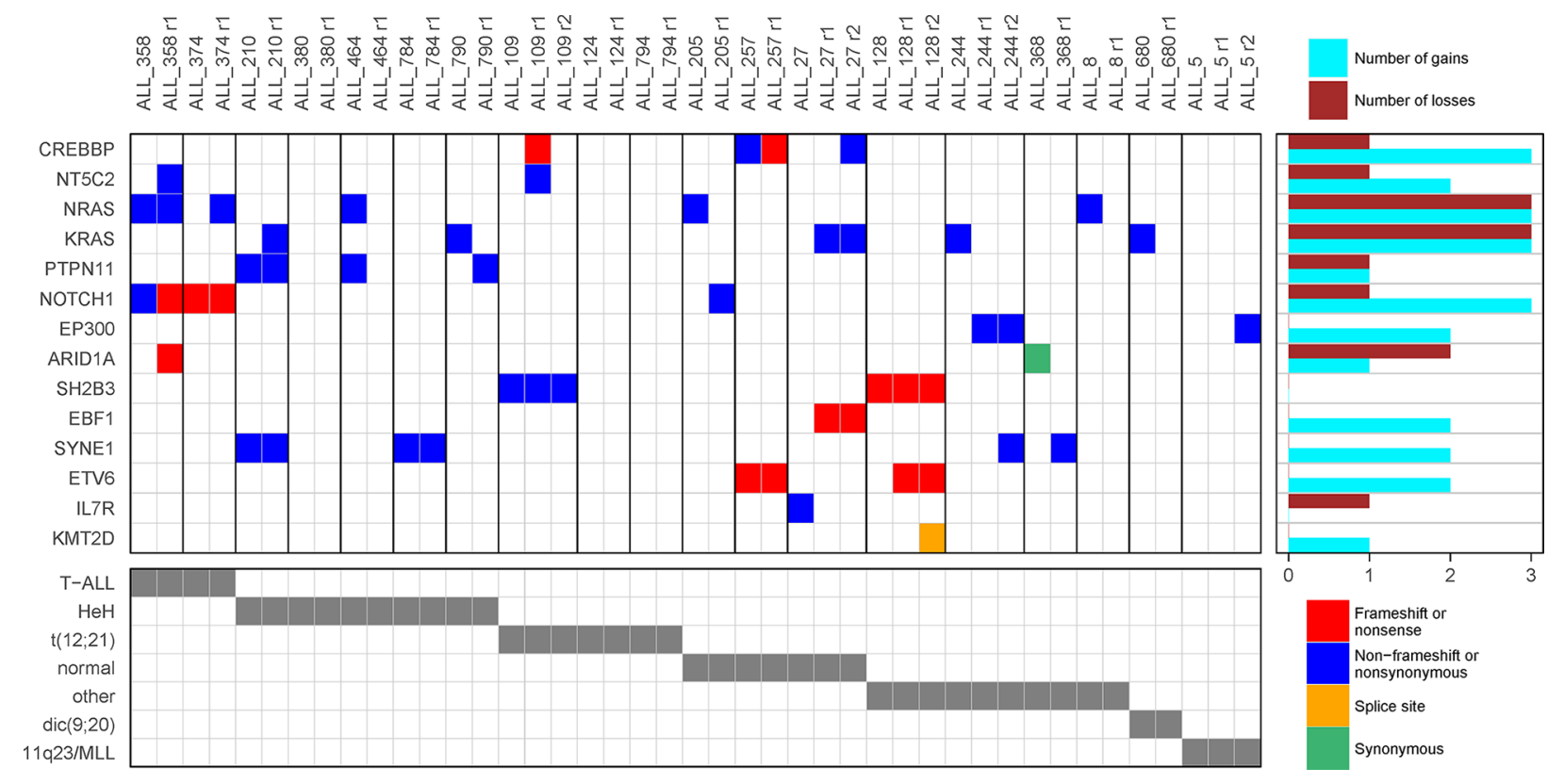

Figure 5: Gain and loss of driver mutations at relapse of acute lymphoblastic leukemia (ALL). Putative driver mutations detected at diagnosis and relapse in 19 ALL patients from whom relapse samples were sequenced. Each column represents an ALL sample with vertical black lines to mark separation between patients. Samples from the same patient are sorted chronologically (diagnosis, first relapse, second relapse). In the main panel, each row represents a gene and each colored box indicates a mutation. For samples with more than one mutation in the same gene, the color is prioritized according to the order shown in the legend. The numbers of gained and lost mutations are summarized to the right of the main panel for each gene. The genetic subtype of each patient is shown in grey in the lower panel. 
A

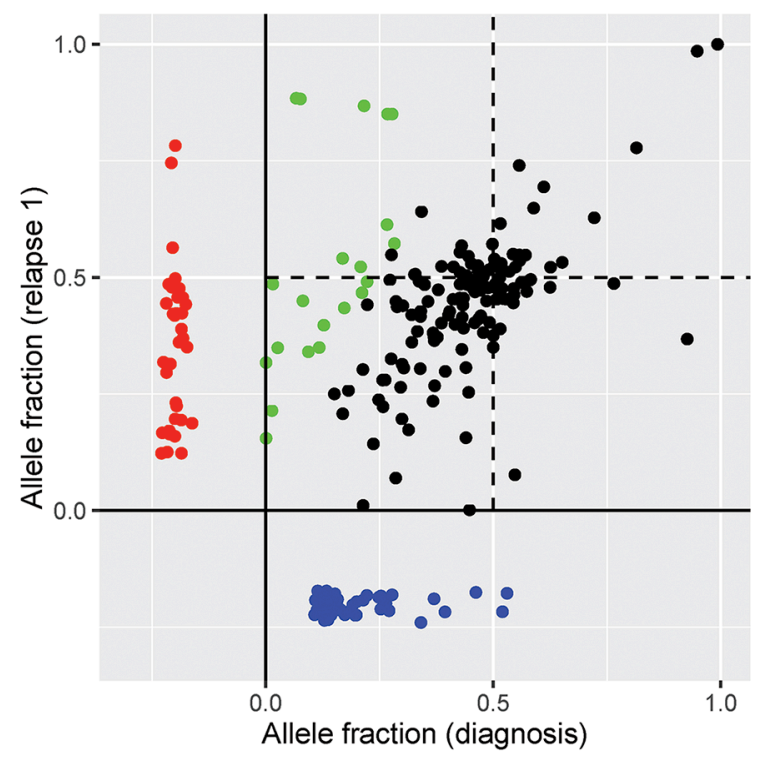

C

ALL_244 (BCP-ALL other)

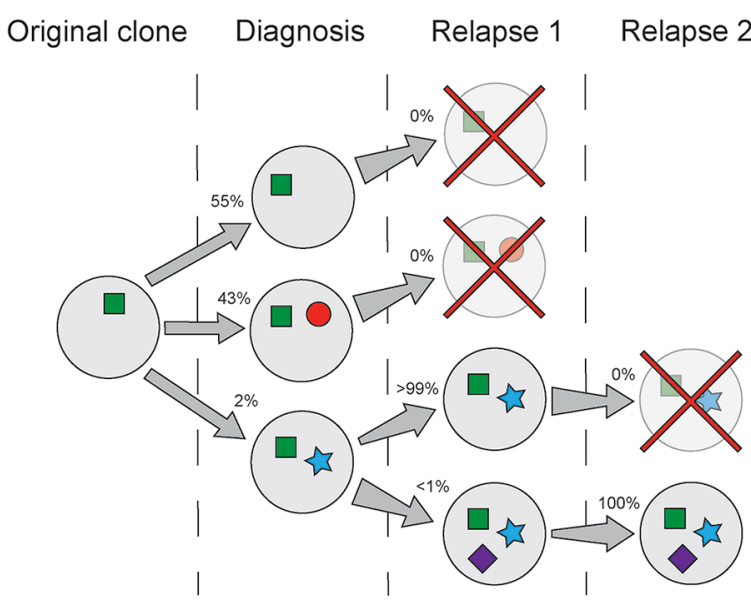

$+\mathrm{X}, \mathrm{t}(1 ; 15), \mathrm{t}(3 ; 10)$

KRAS.G12D

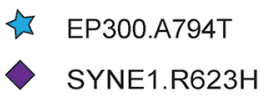

B

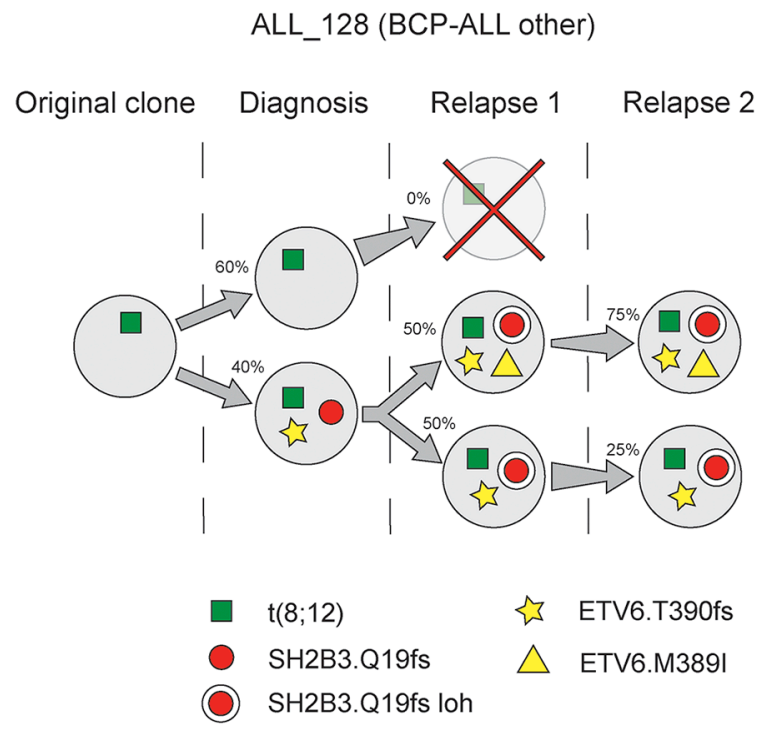

D

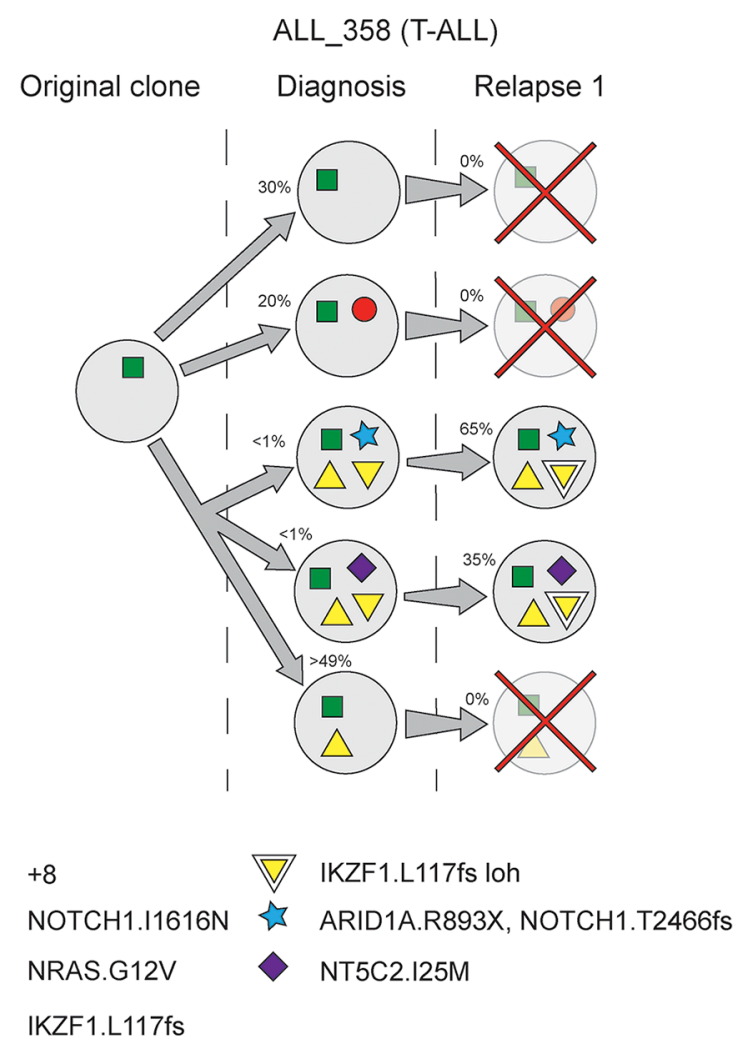

Figure 6: Clonal evolution of acute lymphoblastic leukemia (ALL) cells. (A) Allele fractions of somatic mutations detected in the 19 patients from whom relapse samples were sequenced. Mutations detected at both diagnosis and relapse are shown in the large square, and those with indications of being part of rising clones are highlighted in green. The rectangular areas at the bottom and the left show mutations only detected at diagnosis (blue) and relapse (red), respectively. (B-D) Examples of clonal evolution patterns in the BCPALL patients ALL_128 and ALL_244 with non-recurrent clonal aberrations, and in T-ALL patient ALL_358. Each circle represents an inferred subclone, marked with the estimated percentage of leukemic cells in this clone. The green squares represent aberrations detected by cytogenetic analysis. The most important mutations in each clone are shown. A red cross indicates that the clone is inferred to have been eradicated by therapy. A double circle or triangle indicates loss of heterozygosity (loh). The figures illustrate examples of clonal evolution, and do not necessarily represent the only possible evolutionary path in these patients. (B) ALL_128 harbored a subclone with frameshift indels in SH2B3 and ETV6 at diagnosis, which expanded at the first relapse. In addition, an allele fraction of 0.85 for the $S H 2 B 3$ indel 
suggests that the wild type allele of this gene had been lost, and a novel nonsynonymous SNV in ETV6 which appears to be on the other allele than the indel was identified. All mutations remained at the second relapse. (C) Two subclones were inferred at diagnosis in ALL_244, one with a KRAS mutation which was lost at relapse and one with an EP300 mutation which became dominant at the first relapse. At the first relapse we detected a minor clone with a SYNE1 mutation, which became dominant at the second relapse. (D) In ALL_358 we inferred as many as four distinct subclones at diagnosis. One subclone harbored a NOTCH1 mutation and was lost at relapse, and the other three shared an NRAS mutation. The two minor NRAS clones, which expanded at relapse, also harbored ARIDIA and NT5C2 mutations, respectively. At relapse, the ARIDIA clone acquired a novel NOTCH1 mutation.

mutations are required to induce ALL. Our finding that the APOBEC signature of nucleotide substitution is only observed in patients with the ETV6-RUNX1 fusion gene and the previous demonstration of frequent RAGmediated recombination in this subtype [18] suggests that different molecular mechanisms are active in patients with the ETV6-RUNX1 fusion gene than in the other ALL subtypes. Thus it would be interesting to study the mutational patterns in larger cohorts of patients with other recurrent fusion genes. Patients of the $\mathrm{HeH}$ subtype stood out as having many driver mutations, in particular in the Ras pathway. In contrast to a previous study [19], we found no indications of mutual exclusivity between Ras mutations in the $\mathrm{HeH}$ patients.

We found that BCP-ALL patients with mutations in the Notch signaling pathway relapsed frequently. The Notch pathway is a well-known genetic determinant in T-ALL and has been implicated in several other cancers [20]. While the majority of somatic mutations in NOTCH1 in T-ALL are activating and result in aberrant continued signaling [21], a tumor suppressor role of the Notch pathway has been shown in acute myeloid leukemia (AML) $[22,23]$. Although the majority of the Notch pathway mutations detected in our study are predicted to have a functional effect on the protein, there is no evidence suggesting that they would be activating. Thus, it seems reasonable to assume that the mutations in $C R E B B P$, EP300 and MAML, which all encode transcriptional coactivators, could result in reduced Notch signaling. In contrast, $H D A C 2$ and $D T X 1$ are negative regulators of Notch signaling, and mutations in these genes are more likely to result in increased signaling. Given the complex role of the Notch pathway in hematological malignancies, it is not unlikely that different types of disturbances in Notch signaling could be involved in the progress of ALL.

Our results also highlighted the ATRX, EP300, $A R I D 1 A$ and $S H 2 B 3$ genes as novel putative ALL drivers, associated with relapse, or being present in rising clones at relapse. All genes except $A R I D 1 A$ were identified in the $\mathrm{BCP}-\mathrm{ALL}$ patient group. ATRX is a known driver gene in other cancers than ALL [24]. It encodes a chromatin remodelling protein whose activity affects genomic stability and heterochromatin structure. Although the mechanisms by which loss of ATRX leads to cancer progression are unclear, we find that all ATRX mutations detected in our study are predicted to be deleterious.

EP300 is a known target of translocation in ALL [25], and has recently been reported to be recurrently mutated in adult T-ALL [26] and early T-cell precursor
T-ALL [27], but not yet in BCP-ALL. EP300 is also a known driver gene in other types of cancer [28], and germline variants in EP300 have been shown to confer inherited risk of pediatric ALL in a Hispanic population [29]. There is evidence for somatic mutations in the paralogous gene $C R E B B P$ that result in impaired histone acetylation and transcription of $C R E B B P$ target genes, including glucocorticoid-receptor-responsive genes, which may influence response to therapy and the likelihood of relapse in ALL [6]. In light of this evidence, it will be crucial for future studies to investigate the effect of EP300 mutations in ALL.

$A R I D 1 A$ is recurrently mutated in several cancer types, including lymphomas [30]. The encoded protein contains a well conserved DNA-binding domain which is also present in several other proteins with related functions. Interestingly, a putatively relapse-associated mutation in $A R I D 4 B$ has been identified in pediatric T-ALL [31], and $A R I D 5 B$ has been associated with germline susceptibility to pediatric ALL [32]. ARID1A is a chromatin remodeler that appears to act as a tumor suppressor, and decreased expression of $A R I D 1 A$ is associated with poor prognosis in gastric cancer [33] and hepatocellular carcinoma [34]. Previous studies have shown that $97 \%$ of somatic mutations in ARIDIA are inactivating [30], in line with the predictions of the mutations detected in our study. While $30 \%$ of $A R I D 1 A$ mutations in the literature affect both alleles, $73 \%$ of the cases lack protein expression, implicating that haploinsufficiency for $A R I D 1 A$ may be enough to promote tumor formation $[35,36]$. Thus, although the mutations identified in $A R I D 1 A$ in our study were most likely heterozygous, these mutations could be involved in ALL progression.

Homozygous germline mutations in $\mathrm{SH} 2 \mathrm{~B} 3$ have previously been found in familial ALL, and somatic loss of both $S H 2 B 3$ alleles has been described in a few BCPALL patients [37]. $\mathrm{SH} 2 \mathrm{~B} 3$ encodes a lymphocyte adaptor protein that plays a key role in hematopoiesis and has been suggested to be a tumor suppressor [37]. Our study is to our knowledge the first to report a heterozygous loss-offunction mutation in $\mathrm{SH} 2 \mathrm{~B} 3$ at diagnosis that becomes homozygous at relapse, and suggests that the homozygous loss of $\mathrm{SH} 2 \mathrm{~B} 3$ could have been a driving factor for relapse in this patient.

Our analysis of allele fractions at diagnosis and relapse in the deep sequencing data revealed that many apparently relapse-gained mutations were present in minor clones at diagnosis. The targeted approach used here enabled detection of small leukemic subclones 
with one experiment. Our approach is time- and costefficient compared to exome or whole genome sequencing followed by targeted deep-sequencing of sites with somatic mutations, but a smaller proportion of all somatic mutations will be identified. For example, a recent study of clonal evolution in ALL using exome sequencing identified a median of 18 SNVs and indels at diagnosis [9] in comparison to a median of 3 in our study. While a larger set of mutations enables more robust clustering into subclones, we expect that our approach identified the majority of the putative driver mutations and their evolution between diagnosis and relapse.

In summary, by targeted sequencing of cancer genes in ALL samples collected at diagnosis and relapse, we identified distinctive differences in the mutational landscape between the immunophenotypes and genetic subtypes of ALL, discovered $A T R X$ as a novel putative driver gene in ALL and identified EP300, $A R I D 1 A$ and $S H 2 B 3$ as relapse-associated genes. An interesting observation in our study was that germline variants in EP300, SH2B3 and ARID5B have previously been associated with ALL susceptibility. Although the heritability in ALL is low, genome-wide association studies have identified germline mutations in several genes that are also affected by somatic mutations, including IKZF1, ARID5B, CEBPE and CDKN2A [32, 38]. Likewise, studies of familial ALL have revealed inherited mutations in PAX5 [39] and ETV6 [40], both of which are also targets of somatic mutation and chromosomal translocation in ALL. Another interesting feature is that all four genes mentioned above are involved in epigenetic regulation. Somatic mutations in epigenetic regulators play a role in many cancer types, including T-ALL $[41,42]$. In BCP-ALL, it has been shown that mutations in epigenetic regulators are gained during relapse $[8,9]$. Our results are in line with these previous findings, with mutations in EP300, ARID1A and SH2B3 being present in rising clones at relapse. We observed a high degree of clonal heterogeneity and evolution between diagnosis and relapse, which could have implications for the treatment efficiency.

\section{MATERIALS AND METHODS}

\section{Patient samples}

The pediatric ALL patients analyzed in this study were diagnosed and treated at Swedish pediatric oncology centers in Uppsala, Umeå, Stockholm and Gothenburg, according to the Nordic Society for Pediatric Haematology and Oncology (NOPHO) protocols [43]. ALL diagnosis was established by analysis of leukemic cells with respect to morphology, immunophenotype, and cytogenetics. Immunophenotype (BCP-ALL or T-ALL) was defined according to the European Group for the Immunological Characterization of Leukemias. Gene fusions were screened for by fluorescence in situ hybridization (FISH) or reverse transcriptase polymerase chain reaction (RT-PCR). Karyotypes were assigned according to the International System for Human Cytogenetic Nomenclature [44]. DNA and RNA were extracted as described previously [12]. Targeted sequencing of 172 samples collected at diagnosis ("diagnostic cohort") and 24 samples collected at relapse from 19 patients was performed (Table 1, Supplementary Tables S2 and S3). The percent of leukemic cells was at least 80 in the diagnostic samples (median 90\%). For 163 of the 172 patients, a matched germline sample collected during first clinical remission (CR1) was sequenced in pools. We have previously shown, using germline SNPs that were unique for each patient, that 143 of the 163 remission samples were adequately represented in the pools [12]. In addition, a cohort of 165 samples collected at diagnosis ("extension cohort") which were sequenced in pools (Lindqvist et al, manuscript in preparation) and used to further investigate putative relapse-associated genes (Supplementary Table S8). An in-house RNA-sequencing dataset containing 27 BCP-ALL samples and 18 T-ALL samples (Nordlund et al, unpublished data) was used to determine gene expression levels in ALL cells. The study was approved by the Regional Ethical Review Board in Uppsala, Sweden. The study was conducted according to the guidelines of the Declaration of Helsinki, and all patients and/or guardians provided informed consent.

\section{Target capture and next generation sequencing}

The exons of 872 genes related to cancer were selected for resequencing (Supplementary Table S1). Target capture was performed using $200 \mathrm{ng}$ of DNA and reagents from a HaloPlex Target Enrichment kit (Agilent), according to the Automation Protocol Version D.3. The 172 samples in the diagnostic cohort and the 24 relapse samples were enriched individually. Remission samples were enriched in pools of ten samples. The 165 samples in the extension cohort were enriched in pools of ten samples without a unique individual barcode for each sample. However, each sample was present in two pools using a design that enabled assignment of rare somatic mutations to their carrier (Lindqvist et al, manuscript in preparation). In addition, 84 samples from healthy Swedish blood donors were enriched in pools of 21 samples and used for filtering purposes. Paired-end sequencing with 100 bp reads was performed on a HiSeq2000/2500 system (Illumina). The average sequence depth per sample in the target region was $638 \times$ for ALL samples enriched individually (diagnostic cohort and relapse samples), $529 \times$ for ALL samples in pools (extension cohort), 162× for remission samples and $133 \times$ for Swedish blood donors.

\section{Analysis of sequence data}

Variant calling in the diagnostic cohort and relapse samples was performed using FreeBayes (http:// arxiv.org/abs/1207.3907) for SNVs and the GATK 
HaplotypeCaller [45] for indels. Variants were filtered based on sequence coverage, quality scores and germline variants, and annotated against the Ensembl database as described previously [12]. Putative driver genes were identified using MutSigCV [46], Oncodrive-fm [47] and OncodriveCLUST [48] as described previously [12], except that OncodriveCLUST version 0.4.1 was used. For this analysis, the 172 patients in the diagnostic cohort were divided into five subsets: 1) T-ALL, 2) BCPALL, 3) BCP-ALL with $\mathrm{HeH}$, 4) BCP-ALL with the translocation $\mathrm{t}(12 ; 21)$, and 5) BCP-ALL with a normal karyotype. A gene was considered as a putative driver if it was predicted as a driver in at least one of the patient subgroups and harbored at least three non-silent mutations. RNA sequence data was generated and analyzed as described previously [12]. All somatic variants called in the diagnostic cohort or in the relapse samples are listed in Supplementary Tables S4, S6 and S7.

\section{Analysis of mutational signatures}

Signatures of mutational processes were determined using the R package somatic signatures [49]. The analysis was performed on SNVs from the core cohort and from the four previously whole genome sequenced patients [12]. All recurrent SNVs (i.e. SNVs present in more than one patient) were excluded. The samples in the core cohort were divided into the same five groups as described above, except that ALL_370 was analyzed individually. The four whole genome sequenced patients were also analyzed individually. The trinucleotide context of all SNVs was determined using function mutation context and reference sequence from package BSgenome.Hsapiens.UCSC.hg19. Motif frequencies of the groups from the core cohort were then corrected according to differences in motif occurrence in the target region relative to the whole genome using the functions kmerFrequency and normalize motifs. Decomposition of the motif matrix to three signatures was done using non-negative matrix factorization with the function identify signatures. The similarity between mutational signatures identified in our data and previously validated mutational signatures available at http://cancer.sanger.ac.uk/cosmic/signatures was assessed using hierarchical clustering with the agglomeration method complete on a Euclidean distance matrix of the scaled signature matrix.

\section{Analysis of protein structures and protein sequences}

Protein sequence motifs and functional sites were predicted based on ProRule [50] and ProSite [51]. The nsSNVs located in protein domains with determined NMR or X-Ray structure deposited in the Protein Data Bank [52] or homologous structure was visually inspected to predict the effect of nsSNVs on the protein.

\section{Survival analysis}

Survival analysis with Gray's test [53], taking the competing risks death in clinical remission 1 (DCR1), resistant disease and secondary malignancy (SMN) into account, was performed for genes and pathways, assessing the association between clinical outcome (relapse) and mutation status. Only non-silent mutations were included, and samples from infants $(<1$ year $)$ were excluded from the analysis $(n=3)$. Patients were analyzed in the following subgroups: 1) the complete data set, 2) T-ALL samples, 3) BCP-ALL samples, 4) BCPALL samples stratified by risk group (high, intermediate and standard risk), 5) BCP-ALL with $\mathrm{HeH}, 6$ ) BCP-ALL with $\mathrm{t}(12 ; 21)$, and 7) BCP-ALL with normal karyotype. To avoid spurious results caused by small patient groups, only genes and pathways that were mutated in at least five patients were considered. For analysis at the gene level, we compared patients with and without a somatic mutation in each gene. For analysis at the pathway level, we compared patients with and without a somatic mutation in any of the genes belonging to the pathway. Genes were assigned to pathways according to the Kyoto Encyclopedia of Genes and Genomes (http://www.genome.jp/kegg). Multiple testing correction was performed using the Bonferroni method [54], correcting for the number of genes or pathways that harbored non-silent mutations in at least five patients in the specific patient subgroup.

\section{Analysis of relapse-associated genes and clonal evolution}

A gene was defined as putatively relapse-associated if it fulfilled at least one of the following two criteria: 1) we detected at least two non-silent relapse-gained mutations (i.e., mutations called only at relapse) in the gene, or 2) we detected at least one relapse-gained mutation in the gene, and additional mutations at diagnosis in patients in the diagnostic and extension cohorts that relapsed. For genes in the second category, we did not allow non-silent mutations at diagnosis in patients of the same immunophenotype that remained in CR1.

To determine the allele fraction of somatic mutations at time points where they had not been called by FreeBayes, we used the GENOTYPE_GIVEN_ALLELES mode of GATK HaplotypeCaller [45]. For analysis of clonal evolution between diagnosis and relapse, somatic mutations were clustered manually, based on in which of the samples they were detectable and the allele fraction at these different time points. Although the clustering is somewhat arbitrary due to the low number of mutations, it still reflects the dynamics of gained and lost mutations during leukemic progression. A mutation is considered to be part of a rising clone if the allele fraction at relapse is at least twice the allele fraction at diagnosis. 


\section{Statistical analysis}

The number of somatic mutations in different patient subgroups was compared with Wilcoxon rank sum test. Correlation between number of mutations and age at diagnosis was performed using Spearman's rank correlation. Comparisons between the fraction of mutations in the original clone, and the number of driver mutations in different patient subgroups was performed with the chi-square test. The association between number of driver mutations and clinical outcome was tested with a Poisson regression model, excluding 10 BCP-ALL patients and three T-ALL patients with a shorter follow-up time than five years.

\section{ACKNOWLEDGMENTS}

We thank Anna Karin Lannergård, Katja Pokrovskaja, and late Christina Leek for assistance with sample procurement, Andrey Alexeyenko for assistance with pathway analysis, our colleagues from NOPHO and the ALL patients who contributed samples to this study. Next generation sequencing was performed at the SNP\&SEQ Technology Platform in Uppsala, which is part of the National Genomics Infrastructure (NGI) funded by the Swedish Council for Research Infrastructures and Science for Life Laboratory. Computational analysis was performed on resources provided by the Swedish National Infrastructure for Computing (SNIC) through the Uppsala Multidisciplinary Center for Advanced Computational Science (UPPMAX).

\section{CONFLICTS OF INTEREST}

No conflicts to disclose.

\section{GRANT SUPPORT}

This work was supported by grants from the Swedish Foundation for Strategic Research (grant no RBc08008), the Swedish Cancer Society (CAN 2013/504), the Swedish Childhood Cancer Foundation (PR2014-0100), the Swedish Research Council for Science and Technology (C0524801), and the Erik, Karin and Gösta Selanders Stiftelse. DE is supported by a grant from the Knut and Alice Wallenberg Foundation to the Wallenberg Advanced Bioinformatics Infrastructure.

\section{REFERENCES}

1. Inaba $\mathrm{H}$, Greaves $\mathrm{M}, \mathrm{Mullighan} \mathrm{CG}$. Acute lymphoblastic leukaemia. Lancet. 2013; 381:1943-1955.

2. Pui CH, Carroll WL, Meshinchi S, Arceci RJ. Biology, risk stratification, and therapy of pediatric acute leukemias: an update. J Clin Oncol. 2011; 29:551-565.
3. Dores GM, Devesa SS, Curtis RE, Linet MS, Morton LM. Acute leukemia incidence and patient survival among children and adults in the United States, 2001-2007. Blood. 2012; 119:34-43.

4. Mullighan CG. The genomic landscape of acute lymphoblastic leukemia in children and young adults. Hematology. 2014; 2014:174-180.

5. Hunger SP, Mullighan CG. Redefining ALL classification: toward detecting high-risk ALL and implementing precision medicine. Blood. 2015; 125:3977-3987.

6. Mullighan CG, Zhang J, Kasper LH, Lerach S, PayneTurner D, Phillips LA, Heatley SL, Holmfeldt L, CollinsUnderwood JR, Ma J, Buetow KH, Pui CH, Baker SD, et al. CREBBP mutations in relapsed acute lymphoblastic leukaemia. Nature. 2011; 471:235-239.

7. Meyer JA, Wang J, Hogan LE, Yang JJ, Dandekar S, Patel JP, Tang Z, Zumbo P, Li S, Zavadil J, Levine RL, Cardozo T, Hunger SP, et al. Relapse-specific mutations in NT5C2 in childhood acute lymphoblastic leukemia. Nat Genet. 2013; 45:290-294.

8. Mar BG, Bullinger LB, McLean KM, Grauman PV, Harris MH, Stevenson K, Neuberg DS, Sinha AU, Sallan SE, Silverman LB, Kung AL, Lo Nigro L, Ebert BL, et al. Mutations in epigenetic regulators including SETD2 are gained during relapse in paediatric acute lymphoblastic leukaemia. Nature communications. 2014; 5:3469.

9. Ma X, Edmonson M, Yergeau D, Muzny DM, Hampton OA, Rusch M, Song G, Easton J, Harvey RC, Wheeler DA, Ma J, Doddapaneni H, Vadodaria B, et al. Rise and fall of subclones from diagnosis to relapse in pediatric B-acute lymphoblastic leukaemia. Nature communications. 2015; 6:6604.

10. Li B, Li H, Bai Y, Kirschner-Schwabe R, Yang JJ, Chen Y, Lu G, Tzoneva G, Ma X, Wu T, Li W, Lu H, Ding L, et al. Negative feedback-defective PRPS1 mutants drive thiopurine resistance in relapsed childhood ALL. Nat Med. 2015; 21:563-571.

11. Andersson AK, Ma J, Wang J, Chen X, Gedman AL, Dang J, Nakitandwe J, Holmfeldt L, Parker M, Easton J, Huether R, Kriwacki R, Rusch M, et al. The landscape of somatic mutations in infant MLL-rearranged acute lymphoblastic leukemias. Nat Genet. 2015; 47:330-337.

12. Lindqvist CM, Nordlund J, Ekman D, Johansson A, Moghadam BT, Raine A, Overnas E, Dahlberg J, Wahlberg P, Henriksson N, Abrahamsson J, Frost BM, Grander D, et al. The mutational landscape in pediatric acute lymphoblastic leukemia deciphered by whole genome sequencing. Hum Mutat. 2015; 36:118-128.

13. Alexandrov LB, Nik-Zainal S, Wedge DC, Aparicio SA, Behjati S, Biankin AV, Bignell GR, Bolli N, Borg A, Borresen-Dale AL, Boyault S, Burkhardt B, Butler AP, et al. Signatures of mutational processes in human cancer. Nature. $2013 ; 500: 415-421$.

14. De Keersmaecker K, Atak ZK, Li N, Vicente C, Patchett S, Girardi T, Gianfelici V, Geerdens E, Clappier E, Porcu M, 
Lahortiga I, Luca R, Yan J, et al. Exome sequencing identifies mutation in CNOT3 and ribosomal genes RPL5 and RPL10 in T-cell acute lymphoblastic leukemia. Nat Genet. 2013; 45:186-190.

15. Puente XS, Bea S, Valdes-Mas R, Villamor N, GutierrezAbril J, Martin-Subero JI, Munar M, Rubio-Perez C, Jares P, Aymerich M, Baumann T, Beekman R, Belver L, et al. Non-coding recurrent mutations in chronic lymphocytic leukaemia. Nature. 2015; 526:519-524.

16. Tzoneva G, Perez-Garcia A, Carpenter Z, Khiabanian H, Tosello V, Allegretta M, Paietta E, Racevskis J, Rowe JM, Tallman MS, Paganin M, Basso G, Hof J, et al. Activating mutations in the NT5C2 nucleotidase gene drive chemotherapy resistance in relapsed ALL. Nat Med. 2013; 19:368-371.

17. Alioto TS, Buchhalter I, Derdak S, Hutter B, Eldridge MD, Hovig E, Heisler LE, Beck TA, Simpson JT, Tonon L, Sertier AS, Patch AM. A comprehensive assessment of somatic mutation detection in cancer using whole-genome sequencing. Nature communications. 2015; 6:10001.

18. Papaemmanuil E, Rapado I, Li Y, Potter NE, Wedge DC, Tubio J, Alexandrov LB, Van Loo P, Cooke SL, Marshall J, Martincorena I, Hinton J, Gundem G, et al. RAG-mediated recombination is the predominant driver of oncogenic rearrangement in ETV6-RUNX1 acute lymphoblastic leukemia. Nat Genet. 2014; 46:116-125.

19. Paulsson K, Horvat A, Strombeck B, Nilsson F, Heldrup J, Behrendtz M, Forestier E, Andersson A, Fioretos T, Johansson B. Mutations of FLT3, NRAS, KRAS, and PTPN11 are frequent and possibly mutually exclusive in high hyperdiploid childhood acute lymphoblastic leukemia. Genes Chromosomes Cancer. 2008; 47:26-33.

20. Lobry C, Oh P, Aifantis I. Oncogenic and tumor suppressor functions of Notch in cancer: it's NOTCH what you think. The Journal of experimental medicine. 2011; 208:1931-1935.

21. Weng AP, Ferrando AA, Lee W, Morris JPt, Silverman LB, Sanchez-Irizarry C, Blacklow SC, Look AT, Aster JC. Activating mutations of NOTCH1 in human T cell acute lymphoblastic leukemia. Science. 2004; 306:269-271.

22. Lobry C, Ntziachristos P, Ndiaye-Lobry D, Oh P, Cimmino L, Zhu N, Araldi E, Hu W, Freund J, AbdelWahab O, Ibrahim S, Skokos D, Armstrong SA, et al. Notch pathway activation targets AML-initiating cell homeostasis and differentiation. The Journal of experimental medicine. 2013; 210:301-319. doi: 10.18632/oncotarget.689.

23. Kannan S, Sutphin RM, Hall MG, Golfman LS, Fang W, Nolo RM, Akers LJ, Hammitt RA, McMurray JS, Kornblau SM, Melnick AM, Figueroa ME, ZweidlerMcKay PA. Notch activation inhibits AML growth and survival: a potential therapeutic approach. The Journal of experimental medicine. 2013; 210:321-337.

24. Kannan K, Inagaki A, Silber J, Gorovets D, Zhang J, Kastenhuber ER, Heguy A, Petrini JH, Chan TA, Huse JT. Whole-exome sequencing identifies ATRX mutation as a key molecular determinant in lower-grade glioma. Oncotarget. 2012; 3:1194-1203. doi: 10.18632/oncotarget.689
25. Gocho Y, Kiyokawa N, Ichikawa H, Nakabayashi K, Osumi $\mathrm{T}$, Ishibashi $\mathrm{T}$, Ueno $\mathrm{H}$, Terada $\mathrm{K}$, Oboki $\mathrm{K}$, Sakamoto H, Shioda Y, Imai M, Noguchi Y, et al. A novel recurrent EP300-ZNF384 gene fusion in B-cell precursor acute lymphoblastic leukemia. Leukemia. 2015.

26. Neumann M, Vosberg S, Schlee C, Heesch S, Schwartz S, Gokbuget N, Hoelzer D, Graf A, Krebs S, Bartram I, Blum H, Bruggemann M, Hecht J, et al. Mutational spectrum of adult T-ALL. Oncotarget. 2015; 6:2754-2766. doi: 10.18632/ oncotarget.2218. doi: 10.18632/oncotarget.2218.

27. Zhang J, Ding L, Holmfeldt L, Wu G, Heatley SL, PayneTurner D, Easton J, Chen X, Wang J, Rusch M, Lu C, Chen SC, Wei L, et al. The genetic basis of early T-cell precursor acute lymphoblastic leukaemia. Nature. 2012; 481:157-163.

28. Kim MS, Lee SH, Yoo NJ, Lee SH. Frameshift mutations of tumor suppressor gene EP300 in gastric and colorectal cancers with high microsatellite instability. Human pathology. 2013; 44:2064-2070.

29. Piwkham D, Gelfond JA, Rerkamnuaychoke B, Pakakasama S, Rebel VI, Pollock BH, Winick NJ, Collier AB, 3rd, Tomlinson GE, Beuten J. Multilocus association of genetic variants in MLL, CREBBP, EP300, and TOP2A with childhood acute lymphoblastic leukemia in Hispanics from Texas. Cancer epidemiology, biomarkers \& prevention. 2011; 20:1204-1212.

30. Wu JN, Roberts CW. ARID1A mutations in cancer: another epigenetic tumor suppressor? Cancer discovery. 2013; $3: 35-43$.

31. Kunz JB, Rausch T, Bandapalli OR, Eilers J, Pechanska P, Schuessele S, Assenov Y, Stutz AM, Kirschner-Schwabe R, Hof J, Eckert C, von Stackelberg A, Schrappe M, et al. Pediatric T-cell lymphoblastic leukemia evolves into relapse by clonal selection, acquisition of mutations and promoter hypomethylation. Haematologica. 2015; 100:1442-1450.

32. Trevino LR, Yang W, French D, Hunger SP, Carroll WL, Devidas M, Willman C, Neale G, Downing J, Raimondi SC, Pui CH, Evans WE, Relling MV. Germline genomic variants associated with childhood acute lymphoblastic leukemia. Nat Genet. 2009; 41:1001-1005.

33. Yan HB, Wang XF, Zhang Q, Tang ZQ, Jiang YH, Fan HZ, Sun YH, Yang PY, Liu F. Reduced expression of the chromatin remodeling gene ARID1A enhances gastric cancer cell migration and invasion via downregulation of E-cadherin transcription. Carcinogenesis. 2014; 35:867-876.

34. He F, Li J, Xu J, Zhang S, Xu Y, Zhao W, Yin Z, Wang X. Decreased expression of ARID1A associates with poor prognosis and promotes metastases of hepatocellular carcinoma. Journal of experimental \& clinical cancer research. 2015; 34:47.

35. Jones S, Wang TL, Shih Ie M, Mao TL, Nakayama K, Roden R, Glas R, Slamon D, Diaz LA, Jr., Vogelstein B, Kinzler KW, Velculescu VE, et al. Frequent mutations of chromatin remodeling gene ARID1A in ovarian clear cell carcinoma. Science. 2010; 330:228-231. 
36. Wiegand KC, Shah SP, Al-Agha OM, Zhao Y, Tse K, Zeng T, Senz J, McConechy MK, Anglesio MS, Kalloger SE, Yang W, Heravi-Moussavi A, Giuliany R, et al. ARID1A mutations in endometriosis-associated ovarian carcinomas. N Engl J Med. 2010; 363:1532-1543.

37. Perez-Garcia A, Ambesi-Impiombato A, Hadler M, Rigo I, LeDuc CA, Kelly K, Jalas C, Paietta E, Racevskis J, Rowe JM, Tallman MS, Paganin M, Basso G, et al. Genetic loss of SH2B3 in acute lymphoblastic leukemia. Blood. 2013; 122:2425-2432.

38. Yang JJ, Cheng C, Devidas M, Cao X, Fan Y, Campana D, Yang W, Neale G, Cox NJ, Scheet P, Borowitz MJ, Winick NJ, Martin PL, et al. Ancestry and pharmacogenomics of relapse in acute lymphoblastic leukemia. Nat Genet. 2011; 43:237-241.

39. Shah S, Schrader KA, Waanders E, Timms AE, Vijai J, Miething C, Wechsler J, Yang J, Hayes J, Klein RJ, Zhang J, Wei $\mathrm{L}$, Wu G, et al. A recurrent germline PAX5 mutation confers susceptibility to pre-B cell acute lymphoblastic leukemia. Nat Genet. 2013; 45:1226-1231.

40. Moriyama T, Metzger ML, Wu G, Nishii R, Qian M, Devidas M, Yang W, Cheng C, Cao X, Quinn E, Raimondi S, Gastier-Foster JM, Raetz E, et al. Germline genetic variation in ETV6 and risk of childhood acute lymphoblastic leukaemia: a systematic genetic study. Lancet Oncol. 2015; 16:1659-1666.

41. Peirs S, Van der Meulen J, Van de Walle I, Taghon T, Speleman F, Poppe B, Van Vlierberghe P. Epigenetics in T-cell acute lymphoblastic leukemia. Immunological reviews. 2015; 263:50-67.

42. Huether R, Dong L, Chen X, Wu G, Parker M, Wei L, Ma J, Edmonson MN, Hedlund EK, Rusch MC, Shurtleff SA, Mulder HL, Boggs K, et al. The landscape of somatic mutations in epigenetic regulators across 1,000 paediatric cancer genomes. Nature communications. 2014; 5:3630.

43. Schmiegelow K, Forestier E, Hellebostad M, Heyman M, Kristinsson J, Soderhall S, Taskinen M. Long-term results of NOPHO ALL-92 and ALL-2000 studies of childhood acute lymphoblastic leukemia. Leukemia. 2010; 24:345-354.

44. Shaffer LG, McGowan-Jordan J, Schmid M. (2013). ISCN (2013): An International System for Human Cytogenetic Nomenclature. (Basel: S. Karger).

45. DePristo MA, Banks E, Poplin R, Garimella KV, Maguire JR, Hartl C, Philippakis AA, del Angel G, Rivas MA, Hanna M, McKenna A, Fennell TJ, Kernytsky AM, et al. A framework for variation discovery and genotyping using next-generation DNA sequencing data. Nat Genet. 2011; 43:491-498.

46. Lawrence MS, Stojanov P, Polak P, Kryukov GV, Cibulskis K, Sivachenko A, Carter SL, Stewart C, Mermel CH, Roberts SA, Kiezun A, Hammerman PS, McKenna A, et al. Mutational heterogeneity in cancer and the search for new cancer-associated genes. Nature. 2013; 499:214-218.

47. Gonzalez-Perez A, Lopez-Bigas N. Functional impact bias reveals cancer drivers. Nucleic Acids Res. 2012; 40:e169.
48. Tamborero D, Gonzalez-Perez A, Lopez-Bigas N. OncodriveCLUST: exploiting the positional clustering of somatic mutations to identify cancer genes. Bioinformatics. 2013; 29:2238-2244.

49. Gehring JS, Fischer B, Lawrence M, Huber W. SomaticSignatures: inferring mutational signatures from single-nucleotide variants. Bioinformatics. 2015; 31:3673-3675.

50. Sigrist CJ, De Castro E, Langendijk-Genevaux PS, Le Saux V, Bairoch A, Hulo N. ProRule: a new database containing functional and structural information on PROSITE profiles. Bioinformatics. 2005; 21:4060-4066.

51. Sigrist CJ, de Castro E, Cerutti L, Cuche BA, Hulo N, Bridge A, Bougueleret L, Xenarios I. New and continuing developments at PROSITE. Nucleic Acids Res. 2013; 41:D344-347.

52. Berman HM, Westbrook J, Feng Z, Gilliland G, Bhat TN, Weissig H, Shindyalov IN, Bourne PE. The Protein Data Bank. Nucleic Acids Res. 2000; 28:235-242.

53. Gray RJ. A class of K-sample tests for comparing the cumulative incidence of a competing risk. Ann Stat. 1988; 16:1141-1154.

54. Dunn OJ. Multiple Comparisons among Means. Journal of the American Statistical Association. 1961; 56:52-\&.

55. Palomero T, Sulis ML, Cortina M, Real PJ, Barnes K, Ciofani M, Caparros E, Buteau J, Brown K, Perkins SL, Bhagat G, Agarwal AM, Basso G, et al. Mutational loss of PTEN induces resistance to NOTCH1 inhibition in T-cell leukemia. Nat Med. 2007; 13:1203-1210.

56. Van Vlierberghe P, Palomero T, Khiabanian H, Van der Meulen J, Castillo M, Van Roy N, De Moerloose B, Philippe J, Gonzalez-Garcia S, Toribio ML, Taghon T, Zuurbier L, Cauwelier B, et al. PHF6 mutations in T-cell acute lymphoblastic leukemia. Nat Genet. 2010; 42:338-342.

57. Thompson BJ, Buonamici S, Sulis ML, Palomero T, Vilimas T, Basso G, Ferrando A, Aifantis I. The SCFFBW7 ubiquitin ligase complex as a tumor suppressor in $\mathrm{T}$ cell leukemia. The Journal of experimental medicine. 2007; 204:1825-1835.

58. Senn HP, Tran-Thang C, Wodnar-Filipowicz A, Jiricny J, Fopp M, Gratwohl A, Signer E, Weber W, Moroni C. Mutation analysis of the N-ras proto-oncogene in active and remission phase of human acute leukemias. International journal of cancer. 1988; 41:59-64.

59. Browett PJ, Norton JD. Analysis of ras gene mutations and methylation state in human leukemias. Oncogene. 1989; 4:1029-1036.

60. Tartaglia M, Martinelli S, Cazzaniga G, Cordeddu V, Iavarone I, Spinelli M, Palmi C, Carta C, Pession A, Arico M, Masera G, Basso G, Sorcini M, et al. Genetic evidence for lineage-related and differentiation stagerelated contribution of somatic PTPN11 mutations to leukemogenesis in childhood acute leukemia. Blood. 2004; 104:307-313. 
61. Armstrong SA, Mabon ME, Silverman LB, Li A, Gribben JG, Fox EA, Sallan SE, Korsmeyer SJ. FLT3 mutations in childhood acute lymphoblastic leukemia. Blood. 2004; 103:3544-3546.

62. Taketani T, Taki T, Sugita K, Furuichi Y, Ishii E, Hanada R, Tsuchida M, Sugita K, Ida K, Hayashi Y. FLT3 mutations in the activation loop of tyrosine kinase domain are frequently found in infant ALL with MLL rearrangements and pediatric ALL with hyperdiploidy. Blood. 2004; 103:1085-1088.

63. Jaffe JD, Wang Y, Chan HM, Zhang J, Huether R, Kryukov GV, Bhang HE, Taylor JE, Hu M, Englund NP, Yan F, Wang Z, Robert McDonald E, et al. Global chromatin profiling reveals NSD2 mutations in pediatric acute lymphoblastic leukemia. Nat Genet. 2013; 45:1386-1391.

64. Shochat C, Tal N, Bandapalli OR, Palmi C, Ganmore I, te Kronnie G, Cario G, Cazzaniga G, Kulozik AE, Stanulla M, Schrappe M, Biondi A, Basso G, et al. Gain-of-function mutations in interleukin-7 receptor-alpha (IL7R) in childhood acute lymphoblastic leukemias. The Journal of experimental medicine. 2011; 208:901-908.

65. Zenatti PP, Ribeiro D, Li W, Zuurbier L, Silva MC, Paganin M, Tritapoe J, Hixon JA, Silveira AB, Cardoso BA, Sarmento LM, Correia N, Toribio ML, et al. Oncogenic IL7R gain-of-function mutations in childhood T-cell acute lymphoblastic leukemia. Nat Genet. 2011; 43:932-939.
66. Leach BI, Kuntimaddi A, Schmidt CR, Cierpicki T, Johnson SA, Bushweller JH. Leukemia fusion target AF9 is an intrinsically disordered transcriptional regulator that recruits multiple partners via coupled folding and binding. Structure. 2013; 21:176-183.

67. Kim S, Zhang Z, Upchurch S, Isern N, Chen Y. Structure and DNA-binding sites of the SWI1 AT-rich interaction domain (ARID) suggest determinants for sequence-specific DNA recognition. The Journal of biological chemistry. 2004; 279:16670-16676.

68. Boller S, Grosschedl R. The regulatory network of B-cell differentiation: a focused view of early B-cell factor 1 function. Immunological reviews. 2014; 261:102-115.

69. Treiber N, Treiber T, Zocher G, Grosschedl R. Structure of an Ebf1:DNA complex reveals unusual DNA recognition and structural homology with Rel proteins. Genes Dev. 2010; 24:2270-2275. 